\title{
LA ARQUITECTURA CONCEPTUAL DEL PRINCIPIO DE SEPARACIÓN DE PODERES*
}

\section{THE CONCEPTUAL STRUCTURE OF THE SEPARATION OF POWER PRINCIPLE}

\author{
Daniel Eduardo Bonilla-Maldonado** \\ Fecha de recepción: 1 de septiembre de 2015 \\ Fecha de aceptación: 14 de octubre de 2015 \\ Disponible en linea: 30 de noviembre de 2015
}

\section{Para citar este artículo/To cite this article}

\author{
Bonilla-Maldonado, Daniel Eduardo, La arquitectura conceptual del \\ principio de separación de poderes, 131 Vniversitas, 231-276 (2015). http:// \\ dx.doi.org/10.11144/Javeriana.vj131.acps \\ doi:10.11144/Javeriana.vj131.acps
}

\footnotetext{
* Artículo de investigación que describe y analiza la estructura conceptual del principio de separación de poderes.

** Profesor asociado, Facultad de Derecho, Universidad de los Andes, Bogotá, Colombia. Obtuvo su doctorado y maestría en derecho en la Universidad de Yale y su título de abogado en la Universidad de los Andes. Agradezco a David Ricardo Luna por su magnífico trabajo como asistente de investigación.
} 


\section{RESUMEN}

El artículo describe y analiza la estructura conceptual del principio de separación de poderes. En consecuencia, describe y analiza las premisas de las que parte, los conceptos básicos que construye, el tipo de sujeto particular que crea y las nociones de tiempo y espacio que compone. El artículo se divide en cuatro partes. En la primera parte, se presentan los componentes centrales de la interpretación dominante hoy en día del principio de separación de poderes. En la segunda parte del artículo, se explora la noción de sujeto que construye el principio de separación de poderes. Este construye un sujeto colectivo, el Estado, que se antropomorfiza y se presenta como un victimario y un sujeto individual, un individuo abstracto que se articula como una víctima del sujeto colectivo. En la tercera parte del escrito, se estudia la noción de tiempo que construye el principio de separación de poderes. El concepto de tiempo tiene dos dimensiones. La primera es la noción circular e infinita del tiempo en que opera el principio. La segunda es la noción de tiempo que se entrecruza con la idea de cambio social que está imbricada en el principio de separación de poderes. En la cuarta y última sección del artículo, examino el concepto de espacio que construye el principio de separación de poderes. La geografía conceptual que elabora el principio tiene múltiples niveles. El principal es el del Estado-Nación. No obstante, el espacio del principio tiene también una dimensión interna y una externa a esta forma de pensar la organización de una comunidad política.

Palabras clave: separación de poderes; análisis cultural del derecho; estado liberal; estado absoluto 


\section{ABSTRACT}

The article describes and analyses the conceptual structure of the principle of separation of powers. As a consequence, it describes and analyzes the premises from which the principle departs, the basic concepts it constructs, the particular type of subject it creates, and the notions of time and space it forms. The article is divided into four parts. The first part presents the key components of the current dominant interpretation of the principle separation of powers. The second part explores the concept of subject constructed by the principle of separation of powers. It constructs a collective subject, the State, which is anthropomorphized and presented as a victimizer and an individual subject, an abstract individual that is articulated as a victim of the collective subject. The third part of the paper, studies the notion of time constructed by the principle of separation of powers. The concept of time has two dimensions. The first is the circular and infinite notion of time in which the principle operates. The second is the notion of time that intersects with the idea of social change that overlaps with the principle of separation of powers. The fourth and last section of the article examines the concept of space constructed by the principle of separation of powers. The conceptual geography elaborated by the principle has multiple levels. The primary one is that of the nation-State. Nevertheless, the space of the principle also has dimensions that are internal and external to this way of thinking about the organization of a political community.

Keywords: separation of powers; cultural analysis of law; liberal state; absolute state.

\section{SUMARIO}

INTRODUCCIÓN.- I. EL PRINCIPIO DE SEPARACIÓN DE PODERES: SUS COMPONENTES BÁSICOS.- II. NATURALEZA Y RAZÓN: EL ESTADO VICTIMARIO Y EL INDIVIDUO VÍCTIMA.- III. EL ETERNO RETORNO.- IV. EL ESTADO-NACIÓN, LA UTOPÍA COSMOPOLITA Y LAS ESTRUCTURAS SUPRANACIONALES.- CONCLUSIONES.- BibliogRAFía. 


\section{INTRODUCCIÓN}

El principio de separación de poderes es uno de los pilares de la arquitectura conceptual del Estado liberal de derecho. Este principio, junto con nociones como democracia, derechos fundamentales e individuo, provee las herramientas centrales para fundamentar y estructurar esta forma de imaginar el Estado ${ }^{1}$. El contenido básico del principio de separación de poderes hace referencia a un tema central para la modernidad ilustrada: el abuso del poder estatal ${ }^{2}$. La premisa de la que parte el principio es que el Estado tiende a abusar de sus atribuciones. Su objetivo, por tanto, es articular y justificar formas para limitarlas. La división en tres ramas busca fragmentar al Estado de manera que las probabilidades de que este viole los derechos de los ciudadanos, sus creadores, disminuyan ${ }^{3}$.

El estudio de este principio usualmente toma alguna de las siguientes cuatro formas. Enfatizo en las diferencias entre los enfoques investigativos para hacer explícitas sus singularidades. No obstante, en la práctica estas aproximaciones se entrecruzan. Un mismo estudio puede tener como objeto de análisis dos o más aristas del principio de separación de poderes. La primera aproximación tiene como objeto de estudio los valores que el principio pretende materializar ${ }^{4}$. Este tipo de trabajos, por tanto, busca examinar las conexiones entre el principio de separación de poderes y valores como la democracia, los derechos fundamentales y la eficiencia estatal ${ }^{5}$. Esta manera de aproximarse al principio de separación de poderes frecuentemente toma la forma de análisis de teoría política o historia de las ideas ${ }^{6}$. Esta perspectiva busca evidenciar los nexos

1 José Fernández-Albertos, Dividir lo indivisible: separación de poderes y soberanía popular en James Madison, 128 Revista de Estudios Políticos, 293-316 (2005). Disponible en: http://digital. csic.es/bitstream/10261/20727/1/REP128.011.pdf

2 José Fernández-Albertos, Dividir lo indivisible: separación de poderes y soberanía popular en James Madison, 128 Revista de Estudios Politicos, 293-316 (2005). Disponible en: http://digital. csic.es/bitstream/10261/20727/1/REP128.011.pdf

3 José Fernández-Albertos, Dividir lo indivisible: separación de poderes y soberanía popular en James Madison, 128 Revista de Estudios Politicos, 293-316 (2005). Disponible en: http://digital. csic.es/bitstream/10261/20727/1/REP128.011.pdf

4 Roberto Mangabeira-Unger, Politics: The Central Texts, 306-339 (Verso, London, 1997).

5 Carlos Santiago Nino, Transition to Democracy, Corporatism, and Presidentialism with Special Reference to Latin America, en Constitutionalism and Democracy: Transitions in the Contemporary World, 46-64 (Douglas Greenberg, Stanley N. Katz, Melanie Beth Oliviero \& Steven Wheatley, eds., Oxford University Press, Oxford, New York, 1993).

6 Enrique Díaz-Bravo, Desarrollo histórico del principio de separación de poderes, 38 Revista 
entre el principio de separación de poderes y las ideas de autores que lo presentan y justifican de manera paradigmática, por ejemplo, Charles-Louis de Secondat, Baron de La Brède et de Montesquieu y John Locke ${ }^{7}$. Del mismo modo, busca reflexionar sobre los valores que el principio debería servir en el presente y sobre las diferencias y similitudes entre tales valores y aquellos que se exponen como centrales en las teorías clásicas.

La segunda perspectiva reflexiona sobre las diversas formas que podría tomar el Estado para materializar el principio de separación de poderes ${ }^{8}$. Este punto de vista, por ende, se concentra en asuntos relacionados con la estructura del Estado. Este tipo de estudios ofrece argumentos detallados sobre las características que tendrían distintas armazones estatales, así como sus ventajas y desventajas 9 . Estos trabajos ofrecen, entre otras cosas, descripciones sobre los modelos presidencialistas, parlamentaristas o mixtos; los grupos poblacionales o de interés que cada rama del poder público debería representar, por ejemplo, por qué la Cámara de Representantes deberían representar a las provincias o estados mientras que el Senado debería representar a toda la nación; la duración de los ciclos electorales de manera que se garantice tanto una rotación saludable de los representantes del pueblo como la estabilidad del Estado; y

de Derecho, Universidad del Norte, 240-270 (2012). Disponible en: http://www.redalyc.org/ pdf/851/85124997008.pdf. Suri Ratnapala, John Locke's Doctrine of the Separation of Powers: A Re-Evaluation, 38 American Journal of Jurisprudence, 1, 189-220 (1993). Disponible en: http:// scholarship.law.nd.edu/cgi/viewcontent.cgi?article $=1205 \&$ context $=$ ajj

7 John Locke y Montesquieu se consideran los autores que presentan de manera paradigmática el principio de separación de poderes. Sin embargo, antes de ellos, autores como Marsilio de Padua y Juan Bodin habían sentado las bases del principio. M. J. C. VILE, Constitucionalismos y separación de poderes, 29, 32 y 64 (Centro de Estudios Políticos y Constitucionales, Madrid, 2007).

8 Rodrigo Uprimny, Separación de poderes y forma de gobierno en Colombia: comentarios al documento de la Misión Alesina, 3 Revista de Economía Institucional, 5, 146-167 (2001). Disponible en: http://www.economiainstitucional.com/pdf/No5/ruprimny5.pdf. SCOTT MaINwARING, Presidentialism, Multipartism, and Democracy: The Difficult Combination, en Flying Blind: Emerging Democracies in East Central Europe, 55-85 (Gyorgy SzoboszlaI, ed., Hungarian Political Science Association, Budapest, 1992). Terry M. Moe \& Michael Caldwell, The Institutional Foundations of Democratic Government: A Comparison of Presidential and Parliamentary Systems, 150 Journal of Institutional and Theoretical Economics, 1, 171-195 (1994). Giovanni SARTORI, Comparative Constitutional Engineering (2a ed., New York University Press, New York, 1997).

9 Michael Laver \& Kenneth A. Shepsle, Making and Breaking Governments: Cabinets and Legislatures in Parliamentary Democracies (Cambridge University Press, Cambridge, 1996). Anthony King, 'Chief Executives' in Western Europe, en Developing Democracy: Comparative Research in Honour of J. F.P. Blondel, 150-163 (IAn Budge \& David McKaY, eds., Sage, London, 1994). 
las combinaciones de frenos y contrapesos que se adecuarían de mejor manera a las distintas comunidades políticas.

La tercera forma de aproximarse al principio de separación de poderes se concentra en su eficacia ${ }^{10}$. Este tipo de análisis evalúa los niveles de efectividad del principio y las consecuencias positivas o negativas que ha generado en comunidades jurídicas particulares ${ }^{11}$. De esta manera, se analiza, por ejemplo, si un sistema de frenos y contrapesos particular ha sido útil para evitar los abusos de poder en un país específico o por qué los efectos que ha tenido una forma de estructurar el Estado — por ejemplo, el presidencialismo — han sido provechosos o inconvenientes en una región particular del mundo. Este tipo de aproximaciones algunas veces asume una perspectiva comparada ${ }^{12}$. El análisis de la forma como opera el principio de separación de poderes en al menos dos jurisdicciones permite explicitar las ventajas y desventajas que cada una tiene para materializar los valores que pretende defender. De esta manera, se examinan, por ejemplo, las razones por las cuales el presidencialismo en Latinoamérica ha contribuido a la producción de caudillismos y a una concentración excesiva del poder creador del derecho en el Ejecutivo, mientras que en Estados Unidos este mismo sistema ha generado otro tipo de consecuencias, entre otras, un sistema estable pero con problemas complejos para la acción estatal. Las ramas Legislativa y Ejecutiva tienden a generar empates negativos que no permiten que una u otra tomen decisiones rápidas y efectivas ${ }^{13}$.

10 Juan J. Linz, Presidential or Parliamentary Democracy: Does It Make a Difference?, en The Failure of Presidential Democracy, 3-89 (JuAn J. Linz \& Arturo Valenzuela, eds., The Johns Hopkins University Press, Baltimore, 1994). Scott Mainwearing \& Matthew S. Shugart, Juan Linz, Presidentialism, and Democracy: A Critical Appraisal, 29 Comparative Politics, 4 , 449-471 (1997). José Antonio Cheibub, Zachary Elkins \& Tom Ginsburg, Latin American Presidentialism in Comparative and Historical Perspective, 89 Texas Law Review, 7, 1707-1740, 1730 (2011). Disponible en: http://www.texaslrev.com/wp-content/uploads/Cheibub-ElkinsGinsburg-89-TLR-1707.pdf

11 Robert Dahl, Thinking about Democratic Constitutions: Conclusions from Democratic Experience, en Political Order: Nomos XXXVIII, 175-206, 191 (IAN Shapiro \& Russell Hardin, eds., New York University Press, New York, 1996). Giovanni Sartori, Neither Presidentialism nor Parliamentarianism, en The Failure of Presidential Democracy, 106-118 (JuAN J. Linz \& Arturo Valenzuela, eds., The Johns Hopkins University Press, Baltimore, 1994).

12 Alfred Stepan \& Cindy Skach, Presidentialism and Parliamentarianism in Comparative Perspective, en The Failure of Presidential Democracy, 119-136 (Juan J. Linz \& Arturo Valenzuela, eds., The Johns Hopkins University Press, Baltimore, 1994). Martin A. Rogoff, A Comparison of Constitutionalism in France and the United States, 49 Maine Law Review, 1, 21-84 (1997). Disponible en: http://mainelaw.maine.edu/wp-content/uploads/2014/01/rogoff-mlr-49.pdf

13 Sarah A. Binder, The Dynamics of Legislative Gridlock, 1947-96, 93 The American Political Science Review, 3, 519-533 (1999). Disponible en: http://www.jstor.org/stable/2585572? 
La cuarta perspectiva es una aproximación normativa al principio de separación de poderes ${ }^{14}$. Esta perspectiva busca criticar las debilidades de las formas comunes de interpretar y concretar el principio ${ }^{15}$, e imaginar nuevas maneras de cargarlo de contenido y materializarlo ${ }^{16}$. En consecuencia, esta forma de acercarse al principio examina, por ejemplo, si sus interpretaciones dominantes encuadran bien con las nuevas realidades sociales de un país o región particulares; si el principio debería interpretarse de manera distinta para las democracias liberales consolidadas y para aquellas que están en proceso de consolidación; si las diferencias entre el principio entendido idealmente y las realidades sociales de los Estados contemporáneos deberían tener como consecuencia una reinterpretación del principio o una transformación de los contextos en donde se aplica; y cuál es la mejor manera de interpretar el principio de separación de poderes de manera que sirva apropiadamente a los valores que dice proteger, entre otros, la democracia, la eficacia estatal y los derechos fundamentales.

Las cuatro formas de aproximarse al principio de separación de poderes son, sin duda, valiosas. Iluminan muchos de sus aspectos centrales. No obstante, estas aproximaciones tienden a enfatizar en dimensiones externas al principio. Acentúan los valores a los que sirve, las estructuras institucionales que debería generar, los efectos que produce y la manera como debería interpretarse de manera que satisfaga nuestros ideales políticos o morales. En este artículo, quisiera complementar el análisis del principio de separación de poderes que ofrecen las perspectivas mencionadas con

seq=1\#page_scan_tab_contents

14 Gabriel L. Negretto, Diseño constitucional y separación de poderes en América Latina, 65 Revista Mexicana de Sociología, 1, $41-76$ (2003). Disponible en: http://www.ejournal.unam. mx/rms/2003-1/RMS03102.pdf. Martin S. Flaherty, The Most Dangerous Branch, 105 Yale Law Journal, 7, 1725-1840 (1996).

15 Daniel Lazare, The Frozen Republic: How The Constitution Is Paralyzing Democracy (Harcourt Brace \& Company, New York, 1996).

16 Diego Fernando Tarapués-Sandino, El tribunal constitucional como poder autónomo en el sistema politico colombiano, 1 Criterio Jurídico, 7, 163-183 (2007). Disponible en: http://revistas. javerianacali.edu.co/index.php/criteriojuridico/article/view/276/1060. AREND LIJPHART, Constitutional Choices for New Democracies, 2 Journal of Democracy, 1, $72-84$ (1991). Disponible en: http://www.researchgate.net/publication/236769539_Constitutional_Choices_for_New_ Democracies. Cass R. Sunstein \& Lawrence Lessig, The President and the Administration, 94 Columbia Law Review, No. 1, 1-123 (1994). Disponible en: http://chicagounbound. uchicago.edu/cgi/viewcontent.cgi?article=11680\&context=journal_articles. JAMES L. SUNDQUIST, Constitutional Reform and Effective Government (rev. ed., The Brookings Institution, Washington, 1992). 
una mirada que se concentre en su arquitectura conceptual. Una mirada que haga explícito el papel que tiene en la construcción de las condiciones de posibilidad del mundo jurídico y político moderno e ilustrado ${ }^{17}$. El principio de separación de poderes contribuye de manera importante, como parte del concepto más amplio del Estado de derecho liberal, a la construcción de la imaginación política y jurídica de todos aquellos que todavía estamos implícita o explícitamente determinados por el proyecto moderno e ilustrado. La modernidad ilustrada sigue condicionando una parte significativa de la teoría y las prácticas de las democracias liberales contemporáneas. Determina la manera como comprendemos una parte central de nuestras prácticas políticas y legales; construye algunos de los componentes de nuestro a priori histórico ${ }^{18}$.

Este artículo, por tanto, explora los distintos niveles que componen la estructura conceptual que tiene actualmente el principio de separación de poderes. En consecuencia, describe y analiza las premisas de las que parte, los conceptos básicos que construye, el tipo de sujeto particular que supone y contribuye $\operatorname{crear}^{19}$ y las nociones de tiempo ${ }^{20}$ y espacio ${ }^{21}$ que compone. El principio de separación de poderes es un elemento central de la cultura moderna e ilustrada. El derecho, como parte de esta cultura, contribuye a la creación de nuestra identidad individual y colectiva. El Estado de derecho liberal constituye una parte nodular del horizonte de perspectivas en el que estamos inmersos. Comprender sus estructuras, por tanto, contribuye a entender quiénes somos, esto es, qué tipo de sujetos y comunidades surgen como consecuencia de las condiciones de posibilidad que ofrece esta forma de cultura.

Para cumplir estos objetivos, el artículo se divide en cuatro partes. En la primera parte, expongo los componentes centrales de la interpretación dominante hoy en día del principio de sepa-

17 Paul W. Kahn, The Cultural Study of Law: Reconstructing Legal Scholarship, 53-54 (Chicago University Press, Chicago, 1999).

18 Paul W. Kahn, The Cultural Study of Law: Reconstructing Legal Scholarship, 53 (Chicago University Press, Chicago, 1999).

19 Paul W. Kahn, The Cultural Study of Law: Reconstructing Legal Scholarship, 77-86 (Chicago University Press, Chicago, 1999).

20 Paul W. Kahn, The Cultural Study of Law: Reconstructing Legal Scholarship, 43-55 (Chicago University Press, Chicago, 1999).

21 Paul W. Kahn, The Cultural Study of Law: Reconstructing Legal Scholarship, 55-77 (Chicago University Press, Chicago, 1999). 
ración de poderes ${ }^{22}$. Este principio, claro, tiene múltiples sentidos. No obstante, hay algunas piezas básicas que generalmente están presentes cuando lo usamos. Este concepto se estructura alrededor de los siguientes cuatro elementos que se complementan: división tripartita del poder público; asignación de funciones distintas a cada una de estas tres ramas del Estado; creación de un sistema de frenos y contrapesos para que se limiten mutuamente; y colaboración armónica para que satisfagan adecuadamente sus funciones.

En la segunda parte del artículo, exploro la noción de sujeto que supone y contribuye a construir el principio de separación de poderes. Por un lado, presupone y ayuda a construir un sujeto colectivo, el Estado, que se antropomorfiza y se presenta como un victimario. Por el otro lado, un sujeto individual, un individuo abstracto que se articula como una víctima del sujeto colectivo. Estos dos sujetos se construyen a partir de una oposición conceptual central para el derecho y la política modernos e ilustrados: razónnaturaleza. Esta oposición se entrecruza con otras tres oposiciones conceptuales para crear el entramado conceptual que da sentido al principio: unidad-fragmentación; omnipotente-limitado; voluntad caprichosa-voluntad sensata.

En la tercera parte del escrito, estudio la noción de tiempo que construye el principio de separación de poderes. El concepto de tiempo tiene dos dimensiones: la noción circular e infinita del tiempo en el que opera el principio y la noción de tiempo que se entrecruza con la idea de cambio social que está imbricada en el principio de separación de poderes. En la cuarta y última sección del artículo, examino el concepto de espacio que construye el principio de separación de poderes. La geografía conceptual que elabora el principio tiene múltiples niveles. El principal nivel es el del Estado-nación. No obstante, el espacio del principio tiene también una dimensión interna (los gobiernos estatales o provinciales) y una externa (la utopía cosmopolita o los gobiernos regionales) a esta forma de pensar la organización de una comunidad política.

22 Enrique Díaz-Bravo, Desarrollo histórico del principio de separación de poderes, 38 Revista de Derecho, Universidad del Norte, 240-270, 268-269 (2012). Disponible en: http://www.redalyc. org/pdf/851/85124997008.pdf 


\section{EL PRINCIPIO DE SEPARACIÓN DE PODERES: SUS COMPONENTES BÁSICOS}

El principio de separación de poderes se estructura alrededor de los siguientes cuatro conceptos: división tripartita del poder público, división funcional entre las tres ramas del Estado, sistema de frenos y contrapesos y colaboración armónica entre los poderes ejecutivo, legislativo y judicial ${ }^{23}$. Estos conceptos tienen diversas interpretaciones y se complementan con otras ideas para dar forma a una versión completa del principio. El precepto es, ciertamente, indeterminado, polisémico y complejo ${ }^{24}$. Cuestiones como los sistemas de elección y representación del pueblo, los tipos de control de constitucionalidad, las formas de articular el veto presidencial y las distintas formas de parlamentarismo, por ejemplo, se entrecruzan con las cuatro nociones centrales mencionadas para darle una forma más precisa e integral al principio. Los significados de unos y otros, además, son múltiples. Se nutren de las diversas tradiciones políticas y teóricas con las que están comprometidos sus intérpretes. No obstante, estos cuatro elementos típicamente aparecen cuando hacemos uso del principio. No es que el concepto tenga unos componentes necesarios y suficientes atemporales. La cuestión es que están presentes, como parte de su estructura básica, en los usos contemporáneos dominantes del principio ${ }^{25}$.

El primer componente, la división tripartita del poder público, está constituido por cuatro argumentos ${ }^{26}$. Por un lado, se asume

23 Juan José Solozábal-Echavarría, Sobre el principio de separación de poderes, 24 Revista de Estudios Políticos, 215-235, 230-234 (1981). Disponible en: http://dialnet.unirioja.es/servlet/ articulo? codigo $=26674$

24 Eorn Carolan, The Problems with the Theory of the Separation of Powers, 5-17. Disponible en: http://ssrn.com/abstract=1889304

25 M. J. C. VILE, Constitucionalismos y separación de poderes, 15-21 (Centro de Estudios Políticos y Constitucionales, CEPC, Madrid, 2007).

26 Montesquieu presenta de manera paradigmática este argumento. En Del Espíritu de las leyes, afirma: "La libertad política de un ciudadano es la tranquilidad de espíritu que proviene de la confianza que tiene cada uno en su seguridad: para que esta libertad exista, es necesario un gobierno tal que ningún ciudadano pueda temer a otro. Cuando el poder legislativo y el poder ejecutivo se reúnen en la misma persona o el mismo cuerpo, no hay libertad; falta la confianza, porque puede temerse que el monarca o el Senado hagan leyes tiránicas y las ejecuten ellos mismos tiránicamente... Todo se habría perdido si el mismo hombre, la misma corporación de próceres, la misma asamblea del pueblo ejerciera los tres poderes: el de dictar las leyes; el de ejecutar las resoluciones públicas y el de juzgar los delitos o los pleitos entre particulares". Charles Louis Secondat de Montesquieu, Del espiritu de las leyes, 104 (Editorial Porrúa, México, 1998). 
que el Estado tiende a abusar del poder que tiene a su disposición ${ }^{27}$. El Estado concentra altos niveles de poder político, jurídico y coercitivo y es inevitable, como la historia lo muestra una y otra vez, que lo use indebidamente. Por el otro lado, se razona que el Estado debe fragmentarse de manera que se haga menos probable que abuse de su poder ${ }^{28}$. La concentración de atribuciones en una sola institución aumenta las probabilidades de que esta las use de manera inapropiada. De igual forma, la división del poder público debe hacerse en tres partes en la medida en que todo Estado debe cumplir tres funciones fundamentales ${ }^{29}$ : crear derecho, administrar la comunidad política siguiendo los mandatos que este impone y resolver conflictos particulares haciendo uso de las reglas y principios jurídicos. El fraccionamiento del Estado debe, por tanto, tener como consecuencia la institucionalización de las ramas legislativa, ejecutiva y judicial del poder público. Finalmente, ningún funcionario podrá ocupar posiciones en más de una de las ramas en las que se divide el Estado. Hacerlo implicaría concentrar el poder en pocas manos. Permitirlo sería aumentar las probabilidades de que los agentes del Estado abusen de su poder. El principio de separación de poderes implica entonces una fragmentación de las instituciones, las funciones y las personas que sirven al Estado.

27 Locke presenta el argumento de manera ilustrativa al criticar el Estado absolutista. Al respecto, señala que el monarca absoluto "al suponerse que debe ejercer en solitario todos los poderes, tanto el legislativo como el ejecutivo, hace que no pueda encontrarse juez alguno, ni quepa la posibilidad de interponer recurso alguno, ni quepa la posibilidad de interponer recurso ante nadie que tenga autoridad para decidir justa e imparcialmente". JoHn LocKe, Segundo tratado sobre el gobierno civil, Capítulo VII, párrafos 90-91 (SKLA, Bogotá, 2012). De igual forma, Locke señala: "En aquellos Estados en los que el poder legislativo recaiga en una sola asamblea permanente y reunida de manera constante, o en un solo hombre, como ocurre en las monarquías absolutas, seguirá existiendo el peligro de que consideren que sus propios intereses son diferentes de los del resto de la comunidad". John Locke, Segundo tratado sobre el gobierno civil, Capítulo XI, párrafo 138 (SKLA, Bogotá, 2012).

28 Charles Louis Secondat de Montesquieu, Del espíritu de las leyes, 104-110 (Editorial Porrúa, México, 1998).

29 En Montesquieu, la división entre tres instituciones y tres funciones es clara, como se puede ver en la nota 26. No obstante, en Locke, como en muchos de sus antecesores, aunque se entiende que el Estado tiene tres funciones, no se entiende que hay tres instituciones. Dos de las funciones son desarrolladas por el poder legislativo. Así, mientras que el ejecutivo administra, el legislador crea normas jurídicas y las aplica a casos particulares. Al respecto, Locke dice: "En todas las monarquías moderadas y en los Estados bien estructurados, los poderes legislativo y ejecutivo eran ejercidos por instancias diferentes". JoHN Locke, Segundo tratado sobre el gobierno civil, Capítulo XIV, párrafo 159 (SKLA, Bogotá, 2012). M. J. C. VILE, Constitucionalismos y separación de poderes, 66 (Centro de Estudios Políticos y Constitucionales, Madrid, 2007). 
El segundo componente estructural del principio indica que la creación de las tres ramas del Estado debe ir de la mano con su aislamiento funcional ${ }^{30}$. El fraccionamiento del Estado puede ser efectivo solo si cada una de ellas cumple una función específica de manera autónoma. La interacción entre las tres ramas abre la posibilidad de acuerdos explícitos o implícitos entre quienes las representan. En la práctica, esto implica una nueva concentración del poder estatal que ineludiblemente lleva a la violación de los derechos de los miembros de la comunidad política. El principio de separación de poderes supone no solo que el Estado debe cumplir tres funciones únicamente, sino que cada una de ellas puede articularse y ponerse en práctica sin tener en cuenta a las otras dos.

El tercer componente complementa el principio de manera que pueda cumplir cabalmente su objetivo de evitar la concentración y abuso del poder estatal. La separación funcional no resulta suficiente para alcanzar este propósito. Los límites entre las competencias que tiene cada rama deben ser tajantes. Sin embargo, cada una de ellas debe también poder controlar a las otras $\operatorname{dos}^{31}$. Las comunidades políticas deben articular un sistema de frenos y contrapesos que haga menos probable la violación de los derechos ciudadanos por parte del Estado ${ }^{32}$. Los instrumentos específicos para llenar

30 Nuevamente, Montesquieu presenta este argumento de manera paradigmática: "No hay libertad si el poder de juzgar no está bien deslindado del poder legislativo y del poder ejecutivo. Si no está separado del poder legislativo, se podría disponer arbitrariamente de la libertad y la vida de los ciudadanos; como que el juez sería legislador. Si no está separado del poder ejecutivo, el juez podría tener la fuerza de un opresor". Charles Louis Secondat de MontesQuIEu, Del espíritu de las leyes, 104 (Editorial Porrúa, México, 1998).

31 La fuente paradigmática de este argumento es El federalista No. 51: The Structure of the Government Must Furnish the Proper Checks and Balances between the Different Departments. En este texto, Madison afirma lo siguiente: ¿A qué expediente recurriremos entonces para mantener en la práctica la división necesaria del poder entre los diferentes departamentos, tal como la estatuye la Constitución? La única respuesta que puede darse es que como todas las precauciones de carácter externo han resultado inadecuadas, el defecto debe suplirse ideando la estructura interior del gobierno de tal modo que sean sus distintas partes constituyentes, por sus relaciones mutuas, los medios de conservarse unas a otras en su sitio... $\mathrm{Y}$, consiguientemente, estar constituido en forma tal que los miembros de cada uno tengan la menor participación posible en el nombramiento de los miembros de los demás. ". Ahora bien, "[...] la mayor seguridad contra la concentración gradual de los diversos poderes en un solo departamento reside en dotar a los que administran cada departamento de los medios constitucionales y los móviles personales necesarios para resistir las invasiones de los demás”. Alexander Hamilton, James Madison \& John Jay, El federalista No. 51, 220 (Fondo de Cultura Económica, FCE, México, 2001).

32 Usualmente, se identifica a Montesquieu con el argumento de la separación funcional. Sin embargo, en Del espíritu de las leyes, él también hace referencia a los frenos y contrapesos. Al respecto, señala: "He aquí, pues la constitución fundamental del gobierno de que habla- 
de contenido este sistema son múltiples y de diversa índole ${ }^{33}$. El principio no se compromete con ninguno de ellos. Los contextos en los que están inmersos las distintas comunidades políticas deben determinar el conjunto de herramientas que les resulta más eficiente.

Así, por ejemplo, para algunos Estados puede ser ideal la combinación entre veto presidencial, control abstracto de constitucionalidad y control político del ejecutivo por parte del legislativo mediante las mociones de censura. No obstante, para otros, dadas sus idiosincrasias culturales y políticas, puede ser más útil la combinación entre control concreto de constitucionalidad, elección de la cabeza del Ejecutivo por parte del Legislativo, juzgamiento de los altos funcionarios de la administración por parte del Congreso y veto presidencial limitado a normas jurídicas que regulen cierto tipo de materias.

Ahora bien, los sistemas de frenos y contrapesos usualmente también incluyen una variable relacionada con los intereses sociales que debería representar cada rama del poder público ${ }^{34}$. El principio de separación de poderes parte de la base de que si el Legislativo, el Ejecutivo y el Judicial se construyen de manera que representan diversos intereses, o los mismos intereses pero de diversa manera, es posible generar dinámicas de control mutuo que pueden moderar el uso del poder o evitar su concentración en pocas manos. Tampoco acá el principio se compromete con algún modelo específico de representación. Cada comunidad política debe escoger el que mejor se adecúe a sus particularidades e ideales políticos. Así, por

mos. Compuesto de dos partes el poder legislativo, la una encadenará a la otra por la mutua facultad del veto. Ambas estarán ligadas por el poder ejecutivo como este por el legislativo". Charles Louis Secondat de Montesquieu, Del espiritu de las leyes, 109 (Editorial Porrúa, México, 1998). M. Elizabeth Magill, The Real Separation in Separation of Powers Law, 86 Virginia Law Review, 6, 1127-1198 (2000). Disponible en: https://law.stanford.edu/publications/ the-real-separation-in-separation-of-powers-law/, http://papers.ssrn.com/sol3/papers. cfm?abstract_id=224797. M. Elizabeth Magill, Beyond Powers and Branches in Separation of Powers Law, 150 University of Pennsylvania Law Review, 2, 603-660 (2001-2002). Disponible en: $\mathrm{http} / /$ scholarship.law.upenn.edu/cgi/viewcontent.cgi?article=3259\&context=penn_law_review

33 Antonio Barreto-Rozo, El proyecto constitucional de la separación de poderes en el Estado colombiano: apuntes sobre su desenvolvimiento a lo largo del siglo XX, 122 Vniversitas, 213-260 (2011). Disponible en: http://www.redalyc.org/pdf/825/82522606009.pdf. Neal Kumar KatYaL, Internal Separation of Powers: Checking Today's Most Dangerous Branch from Within, 115 Yale Law Journal, 9, 2314-2349 (2006). Disponible en: http://www.yalelawjournal.org/essay/ internal-separation-of-powers-checking-todays-most-dangerous-branch-from-within

34 Bruce Ackerman, The New Separation of Powers, 113 Harvard Law Review, 3, 633-729, 643-663 (2000). Disponible en: http://www.law.yale.edu/documents/pdf/Faculty/TheNewSeperation of Powers.pdf 
ejemplo, una colectividad puede determinar que es mejor un sistema en donde la Cámara de Representantes represente al pueblo, el Senado a los estamentos sociales y el Presidente a la Nación; mientras que otra puede considerar que es más útil un sistema unicameral en el que el legislativo represente a los estados de la federación, el presidente al pueblo y las cortes a las comunidades locales.

El cuarto y último componente exige que las tres ramas del poder público colaboren armónicamente para el cumplimiento de sus funciones ${ }^{35}$. Este elemento, por consiguiente, modula los anteriores. Los poderes ejecutivo, legislativo y judicial deben tener funciones distintas y deben controlarse mutuamente. Sin embargo, deben también cooperar para que los fines que persiguen pueden materializarse de manera efectiva ${ }^{36}$. Las complejidades de los Estados modernos requieren que las ramas del poder público se comuniquen e interactúen ${ }^{37}$. No es posible enfrentar adecuadamente los retos de los Estados de derecho liberales si las ramas del poder público se ignoran entre sí. La promoción y protección de los derechos y el sistema democrático usualmente exige la interacción entre las funciones de creación de derecho, aplicación general de sus mandatos y solución de los conflictos sociales que surgen en un campo social determinado.

La concreción de un derecho económico y social como la educación, por ejemplo, demanda la interacción continua de las tres ramas del poder público. El legislativo debe crear leyes que tengan

35 Aleksey Herrera-Robles, Análisis práctico sobre los criterios de distinción de las funciones públicas, 17 Revista de Derecho, Universidad del Norte, 143-161, 147-150 (2002). Disponible en:_rcientificas.uninorte.edu.co/index.php/derecho/article/view/2991

36 Así, por ejemplo, la Constitución colombiana de 1991 indica que: "Son Ramas del Poder Público, la legislativa, la ejecutiva y la judicial. Además de los órganos que las integran existen otros, autónomos e independientes, para el cumplimiento de las demás funciones del Estado. Los diferentes órganos del Estado tienen funciones separadas pero colaboran armónicamente para la realización de sus fines" (itálicas fuera del texto). Constitución Política [Const], 7 de julio de 1991, artículo 113. Versión corregida, 116 Gaceta Constitucional, 20 de julio de 1991, disponible en: http://www.secretariasenado.gov.co/senado/basedoc/constitucion_politica_1991.html

$37 \mathrm{Al}$ respecto, por ejemplo, señala la Corte Constitucional colombiana, "[...] sí, pues si bien es cierto que el principio de separación de poderes es el fundamento para el reconocimiento de la necesaria independencia y autonomía de los diferentes órganos del Estado, a fin de que puedan cumplir cabalmente sus funciones, también lo es que dicho principio debe ser interpretado en función de su vinculación con el modelo trazado en el artículo 113 superior, según el cual cada uno de los órganos del poder público debe colaborar armónicamente para la consecución de los fines estatales". Corte Constitucional, Sentencia C-246-04, 16 de marzo de 2004, magistrada ponente Clara Inés Vargas-Hernández. Disponible en: http://www. corteconstitucional.gov.co/relatoria/2004/C-246-04.htm 
en cuenta tanto las diferentes necesidades educativas de los grupos culturalmente diversos como los límites fiscales que tiene el Estado. Sin embargo, la articulación de un buen proyecto de ley sobre la materia debería tener en cuenta los puntos de vista que tiene el ejecutivo sobre el derecho a la educación. El ejecutivo es el que tiene la experiencia y la información técnica sobre cuestiones como el número y tipo de profesores que exige la etnoeducación. La rama ejecutiva, por tanto, debería tener la posibilidad de presentar proyectos de ley sobre la materia ante el Congreso. Finalmente, las Cortes deberían enfrentar prioritariamente aquellos casos que incluyen problemas centrales que impiden la materialización de este derecho. Por ejemplo, atender eficientemente los casos de corrupción de funcionarios públicos que desvían los recursos destinados a financiar la etnoeducación y castigar a los implicados de manera ejemplarizante. Las Cortes deberían también tener la posibilidad de hacer un control de constitucionalidad de las normas jurídicas sobre etnoeducación.

Los cuatro componentes centrales de la interpretación dominante del principio de separación de poderes pueden entrar en contradicción. Así, podría decirse que la exigencia de colaboración armónica no es compatible con la separación funcional o que los controles mutuos que crea el sistema de frenos y contrapesos exigen un grado de desconfianza o competencia entre las ramas del poder público que no es compatible con su colaboración armónica. No obstante, estos componentes pueden interpretarse de manera que formen un todo coherente. El sistema de frenos y contrapesos y la exigencia de colaboración armónica se pueden entender como complementos a la separación funcional. Surgen tanto de la experiencia histórica que han tenido las diversas comunidades políticas con la aplicación del principio como de los esfuerzos de los teóricos políticos por precisarlo, desarrollarlo y hacerlo más efectivo. En particular, una interpretación caritativa del principio exige aceptar que la separación de funciones no puede ser tajante. El aislamiento de las tres ramas del poder público genera muchos más costos que beneficios. Las complejidades de los Estados contemporáneos exigen que cada rama guarde para sí el núcleo de algunas competencias, pero que al mismo tiempo interactúe con las otras para controlar sus actuaciones y coordinar la materialización de sus fines. 
Ahora bien, el principio de separación de poderes está en tensión con la realidad de muchos Estados contemporáneos ${ }^{38}$. No parece que algunos aspectos comunes de sus prácticas políticas y jurídicas pueden incluirse fácilmente en el principio. Por un lado, hay instituciones estatales como los bancos centrales, las defensorías del pueblo, las contralorías y las procuradurías que no pueden encuadrarse en ninguna de las tres ramas tradicionales del poder público ${ }^{39}$. Por el otro lado, algunas instituciones del Estado cumplen funciones que no se acomodan fácilmente a las distinciones entre las tareas legislativa, ejecutiva y judicial que presupone el principio $^{40}$. La justicia administrativa, el poder legislativo delegado y las sentencias moduladas, por ejemplo, ponen en cuestión la idea de que los Estados tienen solo tres funciones medulares y que cada rama del poder público debería cumplir una y solo una de ellas. Finalmente, algunas instituciones privadas cumplen tareas que históricamente se han considerado como propias del Estado. Así, por ejemplo, los árbitros son una figura común tanto en el derecho administrativo como en el privado. Sus fallos no se diferencian en lo fundamental de los de un juez. Sin embargo, los árbitros no son funcionarios públicos. No hacen parte de las estructuras estatales.

Este texto, sin embargo, no tiene como objetivo reinterpretar el principio de separación de poderes, de manera que se adecúe a estas nuevas realidades; o articular los conceptos originales que lo complementen. Su fin, como se mencionó en la introducción, no es normativo. El objetivo del texto es describir y analizar la arquitectura conceptual que atraviesa al principio. Su objetivo es comprender la manera como los cuatro elementos centrales del concepto de separación de poderes contribuyen a crear la imaginación política y jurídica moderna y, por tanto, a comprender los sujetos que construyen y las nociones de tiempo y espacio que articulan. Las empresas normativas tienen una importancia para la teoría y

38 Andrea lucas-Garín, Nuevas dimensiones del principio de división de poderes en un mundo globalizado, 7 Estudios Constitucionales, 2, 241-253, 245-248 (2009). Disponible en: http://www. redalyc.org/articulo.oa?id=82011841009

39 Andrea lucas-Garín, Nuevas dimensiones del principio de división de poderes en un mundo globalizado, 7 Estudios Constitucionales, 2, 241-253, 245 (2009). Disponible en: http://www. redalyc.org/articulo.oa?id=82011841009

40 AndRea Lucas-Garín, Nuevas dimensiones del principio de división de poderes en un mundo globalizado, 7 Estudios Constitucionales, 2, 241-253, 246 (2009). Disponible en: http://www. redalyc.org/articulo.oa?id=82011841009 
la práctica jurídica y política. Sin embargo, un buen proyecto normativo debe partir de una sólida comprensión del objeto de estudio.

\section{NATURALEZA Y RAZÓN: EL ESTADO VICTIMARIO Y EL INDIVIDUO VÍCTIMA}

El principio de separación de poderes supone y contribuye a construir dos tipos de sujetos interdependientes: un sujeto colectivo y un sujeto individual. El sujeto colectivo que articula es un Estado antropomórfico fragmentado. Esta forma de imaginar el Estado es consecuencia de dos cambios políticos centrales en la modernidad ilustrada: el paso de un Estado legitimado por la religión a un Estado legitimado popularmente y el paso de un Estado monárquico absoluto a un Estado de derecho ${ }^{41}$. La creación del Estado antropomórfico fragmentado que se entrecruza con el principio de separación de poderes es entonces consecuencia de tres movimientos argumentativos centrales para la política moderna e ilustrada: la separación entre religión y política; la distinción entre un soberano ilimitado y un soberano restringido jurídicamente; y la disociación entre el cuerpo del rey y el cuerpo del Estado.

En el Estado absolutista fundamentado teológicamente, el cuerpo del rey se entendía como un instanciación del Estado ${ }^{42}$. No había diferencia entre el cuerpo del monarca legitimado por la divinidad y el cuerpo político. La famosa frase "El Estado soy yo", que se le atribuye a Luis XIV, presenta esta idea de manera paradigmática. El rey es el representante de Dios en la Tierra; su cuerpo se identifica con el del Estado. El representante de Dios es uno y solo uno. Un individuo, un cuerpo, que encarna al Estado.

La modernidad ilustrada rompe este vínculo cuando desplaza a la religión como criterio para legitimar al Estado. Este, aun si es un Estado absolutista, se legitima a partir del acuerdo de voluntades que consiguen los miembros de la comunidad política. El contrato

41 Philipp Jeandrée, A Perfect Model of the Great King, On the Relationship between the Image of Sovereignty and the Legitimacy of Social Order in Modern Political thought, 11 Zeitschrift für Bildkritik, 2, 68-84 (2011). Disponible en: https://rheinsprung11.unibas.ch/fileadmin/ documents/Edition_PDF/Ausgabe02/thema_jeandree.pdf

42 Philipp Jeandrée, A Perfect Model of the Great King, On the Relationship between the Image of Sovereignty and the Legitimacy of Social Order in Modern Political thought, 11 Zeitschrift für Bildkritik, 2, 68-84, 69-70, 82 (2011). Disponible en: https://rheinsprung11.unibas.ch/fileadmin/ documents/Edition_PDF/Ausgabe02/thema_jeandree.pdf 
social es consecuencia del ejercicio de la voluntad de los individuos que quieren pasar del estado de naturaleza al estado civil. El Estado no es ya una persona de carne y hueso particular. El Estado se convierte, él mismo, en una persona. El Estado se subjetiviza y adquiere autonomía. El Estado moderno, que se legitima por la voluntad popular, adquiere vida propia. El Estado es una ficción política, aunque una muy poderosa ${ }^{43}$. En la imaginación moderna, el Estado se presenta como un ser con vida propia ${ }^{44}$. Del cuerpo del rey como encarnación del Estado pasamos a un Estado con cuerpo propio; el Estado tiene voluntad y actúa por sí mismo. Es un Estado que se distancia y distingue tanto de su creador, el pueblo, como de los individuos que lo ponen en operación, los funcionarios públicos.

Este movimiento argumentativo se inicia con Thomas Hobbes. Los seres humanos pasan del estado de naturaleza al estado civil como consecuencia de un acto de voluntad cuyo objetivo es proteger la vida y permitir la prosperidad de todos los asociados. Este acto de voluntad crea un sujeto complejo que tiene dos componentes. Por un lado, la comunidad política que surge del acuerdo de voluntades de "la multitud". La muchedumbre se convierte en un cuerpo político mediante el ejercicio de la autonomía de cada uno de sus miembros. La multitud elige a un tercero para "defenderse de la invasión extranjera y las injurias de unos a otros" " Ese cuerpo político es, en términos de Hobbes, la república. En sus palabras, esta elección “... es algo más que consentimiento o concordia; es una unidad real de todo ello en una y la misma persona, instituída [sic] por pacto de cada hombre con los demás, en forma tal como si cada uno dijera a todos: autorizo y transfiero a este hombre o asamblea de hombres mi derecho a gobernarme a mí mismo, con la condición

43 Thomas Hobbes presenta este argumento de la siguiente manera: "Y, por tanto, lo que hace la ley no es juris prudentia o sabiduría de los jueces subordinados, sino la razón de nuestro hombre artificial que es la república, y su mandato. Y siendo la república en su representación una sola persona, no puede fácilmente brotar ninguna contradicción en las leyes; y cuando así ha de suceder, la razón misma es capaz de suprimirla mediante su interpretación o alteración. En todos los tribunales quien juzga es el soberano, que tiene la representación de la república...". Thомаs Hobвes, Leviatán, 222 (Fondo de Cultura Económica, FCE, México, 1987).

44 Este proceso emerge con Thomas Hobbes. Philipp Jeandrée, A Perfect Model of the Great King, On the Relationship between the Image of Sovereignty and the Legitimacy of Social Order in Modern Political thought, 11 Zeitschrift für Bildkritik, 2, 68-84, 79-80 (2011). Disponible en: https://rheinsprung11.unibas.ch/fileadmin/documents/Edition_PDF/Ausgabe02/thema_jeandree.pdf

45 Thomas Hobbes, Leviatán, 140 (Fondo de Cultura Económica, FCE, México, 1987). 
de que vosotros trasferiréis a él vuestro derecho, y autorizaréis todos sus actos de la misma manera. Hecho esto, la multitud así unida en una persona se denomina REPÚBLICA, en latín, CIVITAS. Esta es la generación de aquel gran LEVIATÁN, o más bien (hablando con más reverencia) de aquel dios mortal, al cual debemos, bajo el Dios inmortal, nuestra paz y nuestra defensa"46 (mayúsculas e itálicas en el original).

Por otro lado, el segundo componente del sujeto complejo, el soberano. La comunidad política no puede actuar por sí misma. Debe elegir a un representante para que actúe en su nombre. Debe delegar sus poderes en un tercero que proteja la vida de las personas y permita que estas vivan una "vida dichosa". La república no es ninguna persona, ni tiene capacidad para hacer nada si no es mediante el representante: “... El que carga con esta persona se denomina SOBERANO y se dice que posee un poder soberano; cualquier otro es su SÚBDITO"47 (mayúsculas en el original). Este soberano puede ser un rey, una asamblea o un pequeño grupo de individuos ${ }^{48}$. La república puede organizarse en forma de monarquía, democracia o aristocracia. Ahora bien, las actuaciones de este soberano se entenderán como las actuaciones de la república. Las decisiones del soberano son las decisiones de la comunidad política en virtud del acuerdo al que llegaron sus miembros para cederle sus poderes naturales.

La idea hobbesiana de que el Estado es una persona con voluntad propia fue ampliamente difundida y compartida durante la Ilustración. Autores como Samuel von Pufendorf ${ }^{49}$, Emer de Vattel ${ }^{50}$

46 Thomas Hobbes, Leviatán, 141 (Fondo de Cultura Económica, FCE, México, 1987).

47 Thomas Hobbes, Leviatán, 141 (Fondo de Cultura Económica, FCE, México, 1987).

48 Thomas Hobbes, Leviatán, 220-221 (Fondo de Cultura Económica, FCE, México, 1987).

49 Samuel von Pufendorf recoge el argumento de Thomas Hobbes. Al respecto afirma: "La definición más apropiada de un Estado Civil parece ser la siguiente: es una Persona Moral compuesta, cuya Voluntad, unida y sujeta por aquellos pactos acordados entre la Multitud, es considerada la Voluntad de todos; con el Fin de que pueda usar y aplicar la Fuerza y Riquezas de las Personas privadas para mantener la Paz y Seguridad común". Samuel von Pufendorf, Of the Law of Nature and Nations, 475 (J. Walthoe, R. Wilkin \& J. Bonwick, London, 1717), citado en Quentin SKINNER, Una genealogía del Estado moderno, 118 Estudios Públicos, 5-56, 35 (2010). Disponible en: http://www.cepchile.cl/dms/archivo_4626_2792/rev118_Skinner.pdf

50 A este respecto, Emer de Vattel señala: "Los estados son cuerpos políticos, sociedades de hombres que se han unido para procurar su seguridad y ventaja mutuas... [El estado es una] persona moral con un entendimiento y voluntad que le son propios". EMER DE VATTEL, The Law of Nations; or, Principles of the Law of Nature, Applied to the Conduct and Affairs of Nations and Sovereigns, 1 (London, 1760). Disponible en: http://oll.libertyfund.org/titles/2246. Quentin Skinner, Una genealogía del Estado moderno, 118 Estudios Públicos, 5-56, 36 (2010). 
y William Blackstone ${ }^{51}$, por ejemplo, lo incorporaron plenamente a sus teorías. La idea de que el Estado es una persona, además, es uno de los legados más influyentes de la teoría política de los siglos XIX y XX ${ }^{52}$. Este concepto sigue haciendo parte central de la forma en que imaginamos los Estados hoy. Ahora bien, una parte de la teoría política contemporánea se ha apartado del contenido metafísico de esta idea a partir de las críticas que se inician con Jeremy Bentham y John Austin y continúan entrado el siglo XX con autores como Harold Laski ${ }^{53}$. Esta parte de la teoría política no entiende al Estado como una persona moral compuesta que tiene vida propia como consecuencia de un contrato social hipotético. El Estado se entiende como una forma de gobierno que actúa a partir de personas concretas ${ }^{54}$.

No obstante, esta aproximación positivista al Estado cede también a las fuerzas antropomorfizadoras de nuestra imaginación. Los rastros del concepto moderno e ilustrado han dejado sus marcas en la manera como imaginamos el Estado. Este, decimos comúnmente, tiene funciones, cumple tareas y puede hacer que sus partes cooperen o se bloqueen mutuamente. El Estado, así sea una estructura burocrática, se presenta como una persona con voluntad propia. La reaparición del Estado persona no es producto de una forma de hablar, de un giro idiomático. El individuo experimenta y concibe al Estado como un ente con vida propia. El derecho internacional,

Disponible en: http://www.cepchile.cl/dms/archivo_4626_2792/rev118_Skinner.pdf

51 William Blackstone, Commentaries on the Laws of England, 52 (Clarendon Press, Oxford, 1765).

52 Según Quentin Skinner, "la concepción... del estado como el nombre que designa a una persona moral distintiva alcanzó una posición casi hegemónica en la Ilustración, y posteriormente pasó a formar parte del derecho público de varios de los mayores países europeos, sobre todo Alemania y Francia... No sería exagerado afirmar que la teoría del estado como una persona ficticia fue uno de los legados más importantes de la Ilustración a la teoría política de Europa continental en el curso del siglo diecinueve y más allá". Quentin SKINNER, Una genealogía del Estado moderno, 118 Estudios Públicos, 5-56, 40 (2010). Disponible en: http://www.cepchile.cl/ dms/archivo_4626_2792/rev118_Skinner.pdf

53 Quentin SkInNer, Una genealogía del Estado moderno, 118 Estudios Públicos, 5-56, 40-46 (2010). Disponible en: http://www.cepchile.cl/dms/archivo_4626_2792/rev118_Skinner.pdf. JEREMY Bentham, A Fragment on Government (J. H. Burns \& H. L. A. Hart, Cambridge, 1776-1988). Jeremy Bentham, An Introduction to the Principles of Morals and Legislation (J. H. Burns \& H. L. A. Hart, Oxford, 1780-1996). John Austin, The Province of Jurisprudence Determined (Wilfrid E. Rumble, Cambridge, 1832-1995). Harold J. LASKI, Authority in the Modern State (Yale University Press, London, 1919). Disponible en: http://constitutiolibertatis.hautetfort. com/files/LaskiHauthority.pdf

54 Quentin Skinner, Una genealogía del Estado moderno, 118 Estudios Públicos, 5-56, 44 (2010). Disponible en: http://www.cepchile.cl/dms/archivo_4626_2792/rev118_Skinner.pdf 
por ejemplo, sigue hoy pensando en el Estado como la persona que constituye la unidad básica del orden jurídico internacional ${ }^{55}$. La antropología jurídica muestra cómo el Estado se sigue interpretando a partir del modelo weberiano que lo caracteriza como un ente abstracto, autónomo e impersonal ${ }^{56}$.

El sujeto individual que presupone y contribuye a crear el principio de separación de poderes es un sujeto autónomo y racional ${ }^{57}$. El sujeto abstracto con el que usualmente se vincula al liberalismo. Un individuo que tiene la capacidad de articular, transformar y materializar sus proyectos de buen vivir y su sentido de la justi$\mathrm{cia}^{58}$. Este sujeto es a la vez el creador del Estado, el que lo pone en funcionamiento y sobre el que recaen sus decisiones. El paso del estado de naturaleza al estado civil requiere la creación del Estado por parte de los individuos. Una vez estructurado, estos mismos sujetos, encarnados, son los que lo ponen en acción y los que sufren las consecuencias de su actuar. El Estado se construye con el fin de servir a sus creadores; tiene como objetivo proteger su vida, propiedad y libertad. No obstante, la creación adquiere vida propia, en parte como consecuencia del principio de separación de poderes. El principio asume que el Estado concentra poder y tiende a abusar del mismo. El Estado, no los funcionarios públicos, es el que tiene agencia, el que no puede evitar hacer un uso indebido del poder a su disposición.

El Estado-persona de Hobbes es absoluto e indivisible. En esta medida, no puede enfrentar adecuadamente este problema. El Estado soberano, además, no está limitado por las leyes civiles. El Estado liberal de derecho, en contraste, es una persona fraccionada. $\mathrm{Su}$ ser se presenta dividido en tres partes. Es un todo fragmentado.

55 Robert L. Oprisko \& Kristopher Kaliher, The State as a Person?: Anthropomorphic Personification vs. Concrete Durational Being, 6 Journal of International and Global Studies, 1, 30-49 (2014). Disponible en: http://papers.ssrn.com/sol3/papers.cfm?abstract_id=2535494. Alexander Wendt, How Not to Argue Against State Personhood: A Reply to Lomas, 31 Review of International Studies, 2, 357-360 (2005). Disponible en: http://www.jstor.org/ stable/40072101?seq=1\#page_scan_tab_contents. Alexander Wendt, The State as Person in International Theory, 30 Review of International Studies, 2, 289-316 (2004). Disponible en: http://www.jstor.org/stable/pdf/20097917.pdf?seq=1\#page_scan_tab_contents

56 Lina Buchely, Más allá del modelo weberiano: el debate sobre las burocracias y el Estado - Ensayo preliminar, en Las Burocracias, 11-95, 25-27 (Akhil Gupta, Michael Lipsky, Aradhana Sharma \& Charles Wright-Mills, Universidad de los Andes, Bogotá, 2014).

57 John Rawls, Liberalismo político, 29-65 (Fondo de Cultura Económica, FCE, Bogotá, 1996).

58 Jeremy Waldron, Theoretical Foundations of Liberalism, 37 The Philosophical Quarterly, 147, 127-150 (1987). 
La unidad del Estado-persona sigue siendo importante para el liberalismo. El reto es cómo componer internamente a este sujeto colectivo para que no abuse del poder que concentra. Sus creadores, los sujetos individuales, tienen el poder de diseñar su maquinaria interna.

El Estado entonces aparece como un agente-victimario mientras que el individuo se imagina como una víctima. El cuerpo del Estado, por consiguiente, debe ser dividido; su poder limitado. El cuerpo del Estado aparece así con tres cabezas que responden a las tres tareas que debe cumplir: crear derecho, ejecutar sus mandatos y resolver los conflictos particulares haciendo uso de sus reglas y principios. La creación, al cobrar vida propia, tiende a violentar los derechos de sus creadores. Los análisis del principio de separación de poderes generalmente pierden de vista la dependencia entre el sujeto individual y el sujeto colectivo que este crea. La reflexión se concentra en el sujeto colectivo. Sin embargo, uno depende del otro. El Estado es creación humana y los humanos necesitan del Estado para sobrevivir y prosperar. Los individuos encarnados, como burócratas, son los que ponen en operación su estructura. El Estado, no obstante, cobra vida propia, victimiza a sus inventores y debe ser fragmentado.

Ahora bien, el sujeto individual tiene una identidad dual: es al mismo tiempo víctima y victimario. Es una víctima cuando el Estado viola sus derechos pero es un victimario cuando como funcionario público pone en acción la burocracia estatal indebidamente. El aparato estatal, aunque se imagina como un sujeto autónomo, no puede actuar sin apelar a sus burócratas. Los empleados públicos son los instrumentos que mantienen aceitados y en funcionamiento los órganos del Estado. Estos individuos, para el principio de separación de poderes, tienden también a abusar de su poder. Dentro del principio de separación de poderes coexiste la idea de un Estado sujeto colectivo y un sujeto individual que es a la vez objeto de las acciones del Estado y el que las lleva efectivamente a la práctica.

Esta discusión teórica se concreta poderosamente en imágenes icónicas de la modernidad ilustrada. En la pintura de Charles LeBrun, una de las figuras centrales de la pintura francesa del siglo 
$\mathrm{XVII}^{59}$, Luis XIV se presenta como el símbolo de la monarquía absoluta. En el centro de la imagen, aparece el rey a caballo. En la parte superior, rodeándolo aparecen tres figuras religiosas: una lleva una corona y un cetro, otra una bandera, y una más una espada y un escudo. En la parte inferior, se despliega un conjunto de animales y personajes mitológicos o reales. Algunos están atacando al monarca y son repelidos por una de las figuras religiosas, un ángel armado. Otros están ya derrotados; sus cuerpos sin vida se apilan bajo los pies del soberano.

El cuerpo del rey es al mismo tiempo cuerpo místico y cuerpo político. Él es el representante de Dios en la Tierra. Es Dios quien le otorga su corona y su cetro. Él es también el Estado. La bandera que sostiene la figura religiosa es el símbolo del poder político que encarna; su cuerpo concentra el poder político. Este cuerpo político es, además, omnipotente. Sus enemigos, con ayuda divina, son derrotados sin miramientos y sin esfuerzos. El rey cabalga impasible sobre los cadáveres de los adversarios que ya fueron derrotados y frente a los que lo serán prontamente. La naturaleza y los hombres están sometidos a su voluntad. El monarca es también indivisible; es el todo. Puede delegar el cumplimiento de las tareas del Estado pero no las transfiere. Él es la bandera, la espada y la corona bendecida por la divinidad.

En contraste, aparece la imagen de la cubierta de la primera edición de El Leviatán, publicada en 1652. Una imagen que el propio Thomas Hobbes contribuyó a diseñar. La imagen está dividida en dos partes. En la parte inferior aparecen los símbolos del poder político y el poder eclesiástico. Dos poderes distintos; dos esferas diferentes. La religión es fundamental para los seres humanos pero pertenece al orden divino, no al orden humano. La fuente de la legitimidad del poder político no es la religión, es la voluntad de los asociados. En la parte superior aparece el Estado soberano, que esta vez toma la forma de la monarquía. El sujeto colectivo complejo aparece en el centro del recuadro. Es al mismo tiempo la multitud convertida en comunidad política y el rey soberano. Es

59 Luis XIV declaró a LeBrun como el mejor pintor de Francia. Hoy se le considera uno de los artistas centrales de la Francia del siglo XVII. Para información introductoria y bibliografía sobre Charles LeBrun: Charles LeBrun, The Most Important Painter in $17^{\text {th }}$ Century France, First Painter to King Louis XIV. Disponible en: http://www.charleslebrun.com/site_anglais/ qui_est_lebrun_english.htm 
un todo que carga en una mano una espada y en la otra un cetro; el poder político y el poder coercitivo del Estado. El sujeto colectivo, además, es una persona, aunque una que está compuesta por todos los asociados, las pequeñas figuras humanas que constituyen el tronco del rey. El Estado toma la forma de un ser humano. Tiene voluntad y capacidad de acción. La ciudad está bajo su dominio. El cuerpo del Estado soberano aparece todopoderoso sobre el pueblo amurallado. Su objetivo es protegerlo pero bien podría destruirlo. Fue creado para salvaguardar la vida y permitir la prosperidad de los que la habitan. No obstante, tiene poder total para determinar los medios para hacerlo. Los súbditos, además, no pueden ya quitarle el mandato a su representante. El contrato social no puede retrotraerse. 


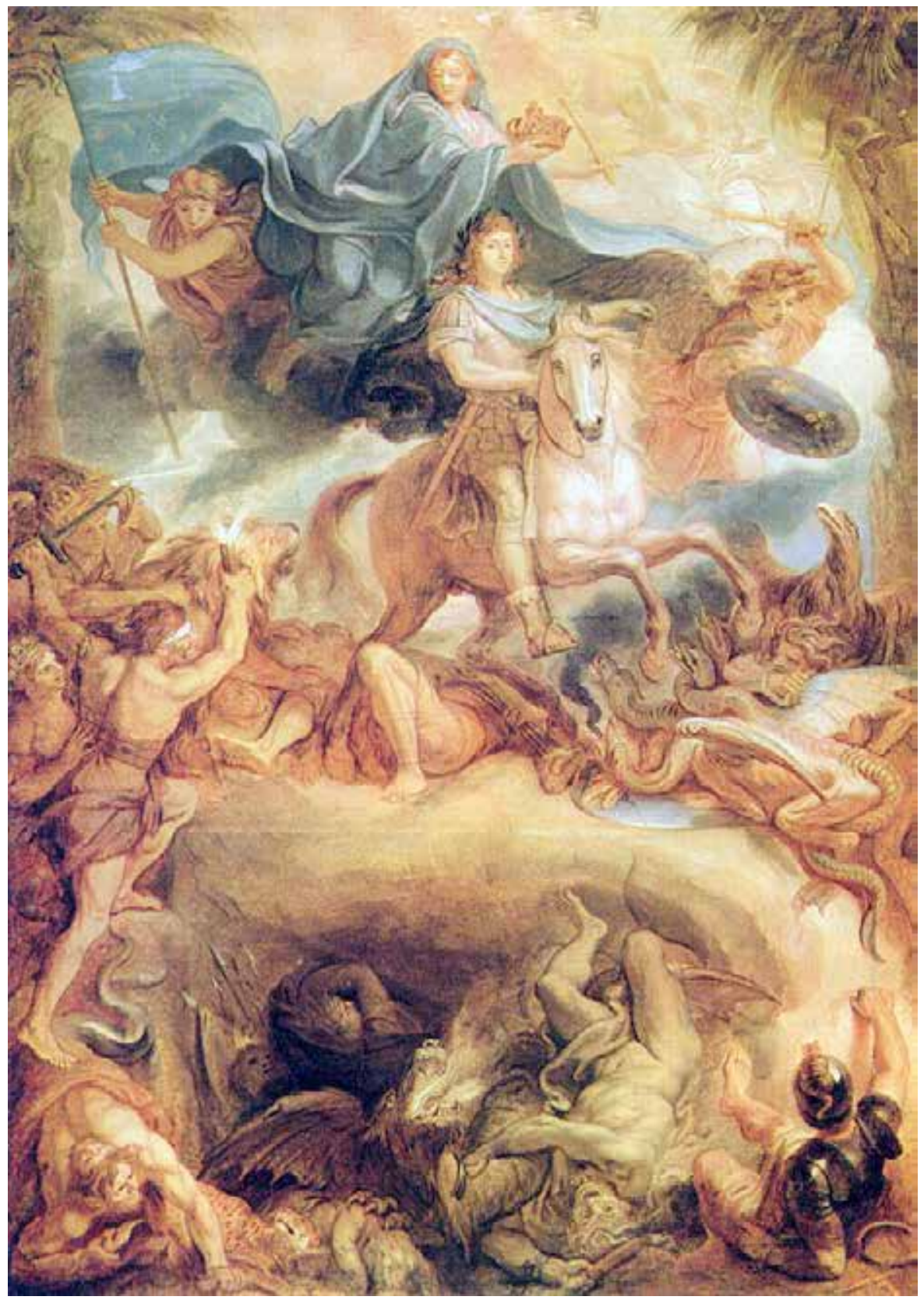

Charles LeBrun, Apoteosis de Luis XIV, 1677, óleo sobre lienzo, Magyar Szépmüvészeti Múzeum, Budapest. 


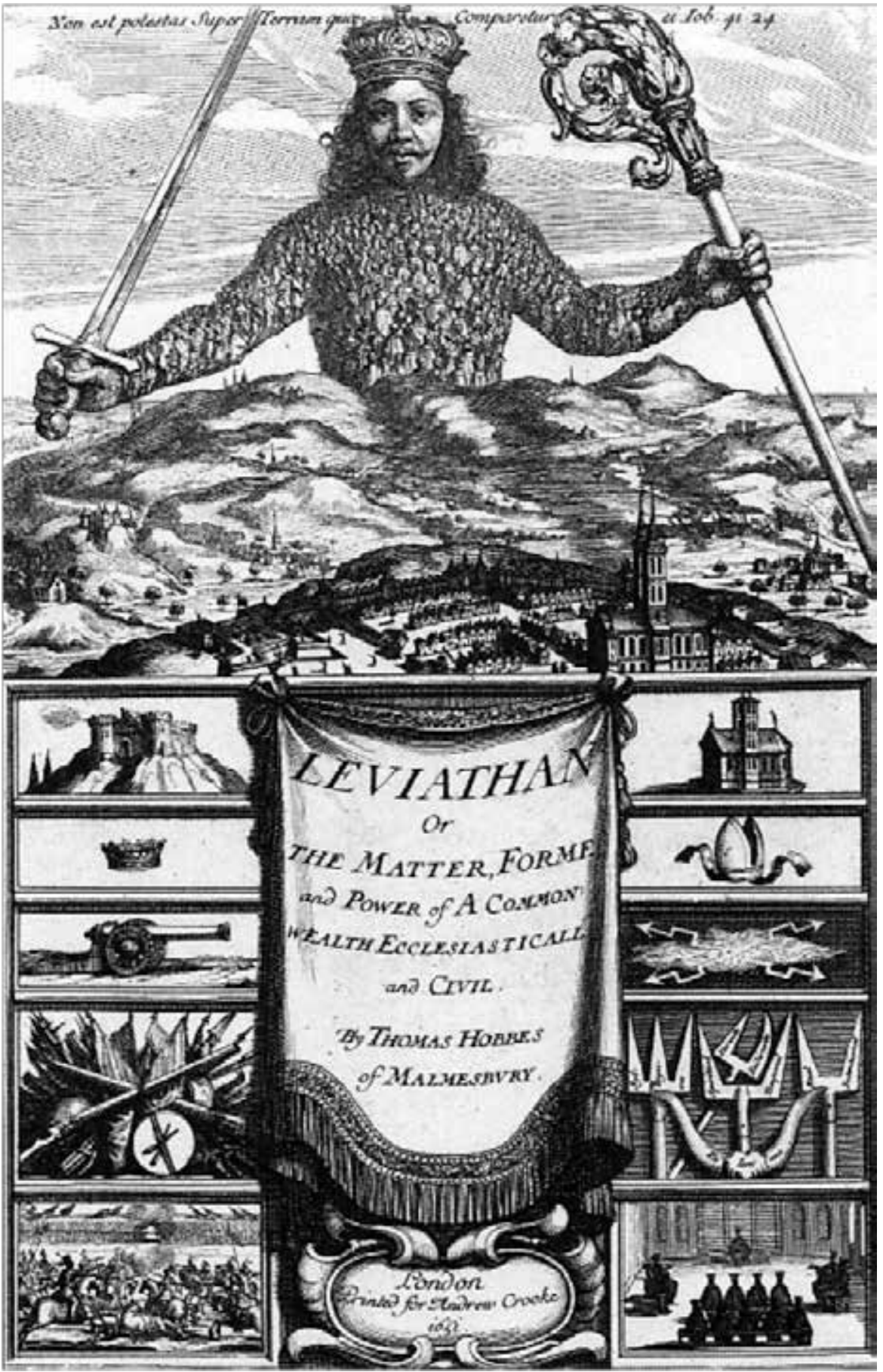

Portada de la edición original de Leviathan. La portada fue diseñada por Abraham Bosse con la intervención directa de Thomas Hobbes, 1651. 
El desplazamiento del cuerpo unitario del rey-Estado del absolutismo al cuerpo fraccionado en tres partes del Estado moderno e ilustrado no es consecuencia del azar; no es una anomalía teórica. Este movimiento argumentativo se hunde en las estructuras conceptuales que sostienen la modernidad ilustrada. En particular, este movimiento argumentativo, que se conecta estrechamente con el principio de separación de poderes, es consecuencia de la oposición entre naturaleza y razón ${ }^{60}$. Por un lado, la oposición subyace a la construcción de los dos sujetos que articula el principio, uno colectivo y otro individual, que no pueden dejar de abusar del poder que concentran ${ }^{61}$. Tienden naturalmente a usar indebidamente las potestades y las fuerzas que reúnen ${ }^{62}$; están constituidos de tal forma que ineludiblemente violarán los derechos de los otros ${ }^{63}$. La naturaleza humana y la naturaleza del Estado, ahora con agencia propia, hacen de este un hecho ineludible.

60 La tradición contractualista, central en la Ilustración, tiene como uno de sus ejes la tensión entre naturaleza y razón. La razón es el instrumento que guía la voluntad para dar el paso del estado de naturaleza al estado civil. David Boucher \& Paul Kelly, The Social Contract and its Critics: An Overview, en The Social Contract from Hobbes to Rawls, 1-34, 4-10 (DAvID Boucher \& Paul Kelly, eds., Routledge, London, 2005). David Gauthier, The Social Contract as Ideology, 6 Philosophy \& Public Affairs, 2, 130-164, 135, 138 (1977).

61 Al respecto, John Locke señala: "Puede ser una tentación excesiva para la fragilidad humana, siempre dispuesta a aferrarse al poder, el que las mismas personas que tienen en sus manos el poder de hacer las leyes tengan también el poder de ponerlas en ejecución, ya que esto podría llevarlas a excusarse de obedecer las leyes que ellos mismos crean, o a adaptar la concepción y ejecución de la ley a su propia conveniencia". JoHn Locke, Segundo tratado sobre el gobierno civil, Capítulo XII, párrafo 143 (SKLA, Bogotá, 2012).

62 En la interpretación de Montesquieu, “....y nos ha enseñado una experiencia eterna que todo hombre investido de autoridad abusa de ella. No hay poder que no incite al abuso, a la extralimitación”. Charles Louis Secondat de Montesquieu, Del espíritu de las leyes, 103 (Editorial Porrúa, México, 1998).

63 Hobbes presenta el asunto de la siguiente manera: "De esta igualdad de capacidad se deriva la igualdad de esperanza respecto a la consecución de nuestros fines. Esta es la causa de que si dos hombres desean la misma cosa, y en modo alguno pueden disfrutarla ambos, se vuelven enemigos, y en el camino que conduce al fin (que es, principalmente su propia conservación y a veces su delectación tan solo) tratan de aniquilarse o sojuzgarse uno a otro. [...] Así hallamos en la naturaleza del hombre tres causas principales de discordia. Primera, la competencia; segunda, la desconfianza; tercera, la gloria”. Тномаs HobBes, Leviatán, 101-102 (Fondo de Cultura Económica, FCE, México, 1987). 
La naturaleza de estos dos sujetos no puede ser cambiada. Sin embargo, puede ser controlada ${ }^{64}$; se le pueden imponer límites ${ }^{65}$. De ahí que surjan el derecho y el principio político de separación de poderes, ambos creaciones de la razón ${ }^{66}$. La razón aparece entonces como un instrumento que construye artefactos que pueden contener a la naturaleza. Las normas jurídicas son el dispositivo que fabrica para controlar la naturaleza del sujeto individual ${ }^{67}$. Le indican un horizonte normativo que debe ser cumplido y que se respalda con una amenaza de castigo. La separación de poderes es el mecanismo que se crea para moderar la voluntad del sujeto colectivo $^{68}$. Al fraccionarse, su poder se debilita. La estructura particular que da forma a este Estado fragmentado determina sus formas de acción. De ahí la riqueza y detalle de las reflexiones sobre la morfología estatal que surgen como consecuencia del principio de separación de poderes. El derecho, claro, también juega un papel

64 Desde la perspectiva de Thomas Hobbes: “... ¿No significa esto acusar a la humanidad con sus actos, como yo lo hago con mis palabras? Ahora bien, ninguno de nosotros acusa con ello a la naturaleza humana. Los deseos y otras pasiones del hombre no son pecados en sí mismos; tampoco lo son los actos que de las pasiones proceden hasta que consta que una ley los prohíbe: que los hombres no puedan conocer las leyes antes de que sean hechas, ni puede hacerse una ley hasta que los hombres se pongan de acuerdo con respecto a la persona que debe promulgarla". Thomas Hobbes, Leviatán, 103 (Fondo de Cultura Económica, FCE, México, 1987).

65 Montesquieu señala a este respecto: "El hombre, como ser físico, es, como los demás cuerpos, gobernado por leyes invariables; como ser inteligente, viola sin cesar las leyes que Dios ha establecido y cambia las que él mismo estableció. Es preciso que él se gobierne; y sin embargo es un ser limitado: está sujeto a la ignorancia y al error, como toda inteligencia finita. Los débiles conocimientos que tiene, los pierde. Como criatura sensible, es presa de mil pasiones. Un ser así, pudiera olvidar en cualquier momento a su creador: Dios lo retiene por las leyes de la religión; semejante ser pudiera en cualquier momento olvidarse de sí mismo; los filósofos lo previenen por las leyes de la moral; creado para vivir en sociedad, pudiera olvidarse de los demás hombres: los legisladores le llaman a sus deberes por medio de las leyes políticas y civiles". Charles Louis Secondat de Montesquieu, Del espiritu de las leyes, 4 (Editorial Porrúa, México, 1998).

66 En el prefacio a Del espiritu de las leyes, Montesquieu señala: "He sentado los principios; he visto los casos particulares ajustarse a ellos, ser consecuencia de ellos las historias de todas las naciones, y cada ley particular relacionada con otra o dependiente de otra más general... No he deducido mis principios de mis prejuicios; los he sacado de la naturaleza de las cosas". Charles Louis Secondat de Montesquieu, Del espiritu de las leyes, 1 (Editorial Porrúa, México, 1998).

67 Aleksey Herrera-Robles, Análisis práctico sobre los criterios de distinción de las funciones públicas, 17 Revista de Derecho, Universidad del Norte, 143-161, 144 (2002). Disponible en: _rcientificas.uninorte.edu.co/index.php/derecho/article/view/2991

68 Aleersey Herrera-Robles, Análisis práctico sobre los criterios de distinción de las funciones públicas, 17 Revista de Derecho, Universidad del Norte, 143-161, 146 (2002). Disponible en: _rrcientificas.uninorte.edu.co/index.php/derecho/article/view/2991 
en la construcción de esta estructura. Las normas jurídicas son las que la formalizan y hacen obligatoria.

El análisis sobre los mecanismos concretos que permiten el cumplimiento de las funciones estatales, su control mutuo y su cooperación puede alcanzar altos grados de abstracción y generalidad ${ }^{69}$. Las características de cada uno de los dispositivos, su relación con los otros y sus ventajas y desventajas pueden precisarse sin hacer referencia a contexto particular alguno. No obstante, cuando el análisis tiene como referencia una comunidad política determinada, la reflexión adquiere un alto grado de especificidad ${ }^{70}$. Los dispositivos y formas institucionales deben adaptarse a las circunstancias propias del contexto para que tengan posibilidades de éxito. Estos esfuerzos argumentativos generales y específicos, estas creaciones de la razón, sin embargo, no podrán nunca transformar la naturaleza del Estado y de los individuos que lo ponen en operación. La naturaleza, tarde o temprano, desbordará los límites que la razón le impone. La razón, por tanto, tendrá que volver a actuar; deberá crear nuevas estructuras, nuevos dispositivos, nuevos fundamentos para intentar contener a la naturaleza. La interacción entre estas dos categorías no tiene final.

Ahora bien, la oposición conceptual entre naturaleza y razón se entrecruza con otras tres oposiciones conceptuales que también subyacen al principio de separación de poderes. En primer lugar aparece la oposición entre unidad y fragmentación. El todo aparece como un riesgo. Se califica negativamente porque implica la concentración de potencias que pueden ser mal utilizadas. La fragmentación, en contraste, se presenta positivamente como una forma de debilitar el todo. La categoría "fragmentación" a su vez se conecta con otras dos oposiciones conceptuales. Por un lado, aislamiento e interacción. Los fragmentos deben separarse uno de otro radicalmente o estos deben interactuar entre sí. La incomunicación entre las partes evita la concentración de poder; su intercambio aumenta su efectividad o modera su capacidad de actuar.

69 Azız Z. HuQ, Libertarian Separation of Powers, 8 New York University Journal of Law and Liberty, 3, 1006-1039 (2013-2014). Disponible en: http://staticl.squarespace.com/static/ 514e1ca0e4b04c6ad1834313/t/55e78d02e4b018b9867be56d/1441238274220/huq.pdf

70 Victoria Nourse, The Vertical Separation of Powers, 49 Duke Law Journal, 3, 749-802 (19992000). Disponible en: http://scholarship.law.duke.edu/cgi/viewcontent.cgi?article=1068\& context $=\mathrm{dlj}$ 
Por el otro lado, aparece la oposición entre interacción para limitar e interacción para la acción conjunta. El contacto entre las partes tiene como objetivo restringir su capacidad de acción o facilitar la gestión colectiva. El diálogo entre los componentes puede estar en función de moderar sus potencias o permitir que alcancen sus objetivos más efectivamente.

En segundo lugar, aparece la oposición conceptual omnipotentelimitado. El todo se presenta como una unidad que puede lograr cualquier cosa que se proponga. La unidad no tiene restricciones. La fragmentación, en contraste, se ofrece como un instrumento para que las partes solo puedan actuar en ciertos campos y siguiendo ciertos procedimientos. Contiene su capacidad de acción. En tercer lugar, voluntad caprichosa y voluntad sensata. El todo omnipotente no tiene más límite que su propia voluntad. Decide sin guía distinta a su propia capacidad volitiva. El todo que se fragmenta reconoce sus límites; su estructura interna le impone fronteras. Al contener las partes, se contiene el todo.

Las cinco oposiciones conceptuales constituyen el aparato conceptual que da sentido y sobre el que se sostiene el principio de separación de poderes. Asimismo, evidencian el papel que juega este principio en la tensión histórica y conceptual entre el Estado absolutista y el Estado de derecho liberal. El monarca absoluto es una unidad todopoderosa; no tiene más límites que su propia voluntad. Como encarnación y símbolo de la comunidad política, no puede ser limitado. La legitimidad de la que goza por voluntad divina no permitiría que su poder fuera limitado terrenalmente. El monarca puede delegar; sus competencias son múltiples y complejas. Sin embargo, sus delegatarios son solo apéndices que cumplen sus mandatos. El Estado liberal de derecho está también comprometido con la unidad del Estado. Su fragmentación interna tiene como objetivo moderar su poder de manera que pueda al mismo tiempo cumplir cabalmente sus funciones y evitar que abuse del inmenso poder que controla. El Estado liberal de derecho es uno y solo uno; pero su estructura, creación de la razón, lo convierte en un organismo internamente heterogéneo. 


\section{EL ETERNO RETORNO}

El tiempo del principio de separación de poderes es circular e infinito. Dado que tiene como base la tensión entre naturaleza y razón, el principio nunca podrá desaparecer del Estado de derecho liberal. Nunca podrán dejar de interactuar. La naturaleza de los sujetos que construye, el Estado y el individuo abstracto, no puede transformarse. La razón, aun empleada de la manera más aguda posible, no tiene la posibilidad de modificar sus componentes esenciales. La interacción entre razón y naturaleza es imperecedera. El Estado de derecho liberal girará eternamente sobre sí mismo. La razón podrá crear variaciones de las estructuras que lo componen pero nunca podrá evitar que abuse de su poder. La razón tampoco podrá crear límites institucionales que eliminen la corrupción de los sujetos que ponen en operación el armazón estatal. En el principio de separación de poderes no hay progreso efectivo; solo en apariencia. No hay un final ideal al que se pueda llegar al superar una serie de etapas preestablecidas. El tiempo del principio no es lineal; no está conformado por una sucesión de puntos que pueda llevarnos al fin de la historia. El Estado liberal de derecho vuelve sobre sí mismo ilimitadamente. En el proceso, sin embargo, muestra tantas variaciones de sus formas como la razón pueda imaginar.

Este proceso infinito se hace evidente tanto en los procesos de reforma constitucional que periódicamente experimentan la mayor parte de los Estados contemporáneos como en la literatura especializada ${ }^{71}$. Cuando el Estado alcanza unos niveles intolerables de ineficiencia o corrupción, la comunidad política articula una reforma de sus estructuras institucionales ${ }^{72}$. Así, si la rama judi-

71 La ineficiencia o la corrupción, claro, no son las únicas razones que explican los cambios constitucionales. La adaptación a nuevas circunstancias políticas, económicas o culturales, por ejemplo, también explican estas transformaciones jurídicas. Para un análisis de las razones que explican los cambios constitucionales, Donald Lutz, Toward a Theory of Constitutional Amendment, 88 American Political Science Review, 2, 355-370 (1994). Disponible en: http://www. jstor.org/stable/2944709?seq=1\#page_scan_tab_contents. SANFORD LEVINSON, ed., Responding to Imperfection. The Theory and Practice of Constitutional Amendment (Princeton University Press, Princeton, 1995). Stefan Voigt, Explaining Constitutional Change. A Positive Economics Approach (New Thinking in Political Economy) (Edward Elgar Publishing, London, 1999). Joachim Jens Hesse \& Nevil Johnson, eds., Constitutional Policy and Change in Western Europe (Oxford University Press, Oxford, 1995).

72 Gabriel L. Negretto, The Durability of Constitutions in Changing Environments: Explaining Constitutional Replacement in Latin America (University of Notre Dame, The Helen Kellogg Institute for International Studies, Working Paper No. 350, 2008). Disponible en: http://kellogg. 
cial ha perdido legitimidad porque se ha contaminado de política partidista, se reforma de manera que los jueces sean elegidos por períodos más largos a los existentes mediante procesos como la cooptación o los concursos de méritos. Si la rama judicial ha perdido legitimidad porque se ha distanciado excesivamente de la realidad social y se ha convertido en una institución radicalmente técnica y formalista, se transforma de manera que represente indirectamente los intereses de la gente por medio de una elección que involucre tanto al presidente como al Congreso. En esta reforma, además, los jueces se elegirán por períodos más cortos de manera que pueda haber una mayor rotación en la institución y puedan llegar nuevos funcionarios que estén más conectados con las realidades y necesidades de la comunidad política. Finalmente, si la rama judicial se ha convertido en un obstáculo infranqueable para la reforma social por su excesivo activismo se modifica de manera que se restrinjan sus competencias en materia de control de constitucionalidad. Las variaciones institucionales son innumerables y el cambio ineludible.

Este proceso circular e infinito de abuso del poder, restricción y nuevo abuso del poder se hace aún más evidente en los países que no han logrado consolidar sus Estados de derecho ${ }^{73}$. En algunos de estos países, las normas jurídicas pueden tener un nivel de efectividad bajo pero concentran un poder simbólico alto. En esta medida, los problemas de ineficiencia y corrupción del Estado se solucionan con reformas jurídicas que no necesariamente atacan las causas del problema ${ }^{74}$. Quienes están en el poder pueden indicarles a sus bases que están conscientes del problema y que están tomando decisiones para enfrentarlo. Ahora bien, esto no quiere decir que en los países que han logrado consolidar sus Estados las

nd.edu/publications/workingpapers/WPS/350.pdf. JoAchim Jens Hesse \& NeVIL Johnson, The Agenda of Constitutional Change in Europe: Adaptation, Transformation, and Internationalization, en Constitutional Policy And Change In Western Europe, 371-392 (Joachim Jens Hesse \& Nevil Johnson, eds., Oxford University Press, Oxford, 1995).

73 Ulrich K. Preuss, Patterns of Constitutional Evolution and Change in Eastern Europe, en Constitutional Policy and Change in Western Europe, 95-127 (JoAchim Jens Hesse \& Nevil Johnson, eds., Oxford University Press, Oxford, 1995). Gabriel L. Negretto, The Durability of Constitutions in Changing Environments: Explaining Constitutional Replacement in Latin America (University of Notre Dame, The Helen Kellogg Institute for International Studies, Working Paper No. 350, 2008). Disponible en: http://kellogg.nd.edu/publications/ workingpapers/WPS/350.pdf

74 Mauricio García-Villegas, La eficacia simbólica del derecho: examen de situaciones colombianas, 237-261 (Ediciones Uniandes, Bogotá, 1994). 
dinámicas sean distintas. La diferencia está, principalmente, en que los ciclos de reformas estructurales por medio del derecho pueden ser un poco más largos.

La literatura especializada también refleja la interacción infinita entre naturaleza y razón ${ }^{75}$. Los abogados y los científicos sociales discuten (y discutirán) cíclicamente en sus publicaciones las ventajas que tiene una interpretación del principio de separación de poderes sobre las otras que circulan en el mercado de las ideas jurídicas; las reformas que requiere una u otra comunidad política en su estructura institucional para lograr los objetivos que persigue; las diferentes experiencias que han vivido países con modelos de separación de poderes análogos o disímiles; y las características que debería tener una comunidad política para escoger un sistema de frenos y contrapesos que se considera particularmente efectivo.

El segundo componente del concepto de tiempo que construye el principio de separación de poderes surge a partir de la relación entre las estructuras estatales que este genera y el cambio social. Esta noción del tiempo parte de dos premisas: hay un nexo entre el derecho y la transformación de la sociedad y el diseño institucional que genera el principio de separación de poderes puede determinar los ritmos de algunas de las variaciones que experimenta la colectividad. Las normas jurídicas tienen la capacidad de transformar la sociedad y esta puede acelerarse o frenarse dependiendo de la voluntad de aquellos que imaginan el esqueleto burocrático del Estado. El tiempo que construye el principio puede ser rápido o lento, acompasado o desigual.

Así, por ejemplo, un sistema de frenos y contrapesos muy exigente puede hacer lento el proceso mediante el cual el Estado toma sus decisiones. El sistema puede llevar a que el Congreso y el presidente interactúen de manera constante con el fin de limitarse mutuamente $\mathrm{y}$, por tanto, que ninguno pueda actuar de forma pronta. Del mismo modo, la manera como se estructura cada una de las instituciones determina el ritmo del cambio social. La revisión automática de cierto tipo de normas jurídicas por parte de los tribunales retrasa el momento en que entran en vigencia. El que nunca puedan ser

75 Bruce Ackerman, The New Separation of Powers, 113 Harvard Law Review, 3, 633-729, 643-663 (2000). Disponible en: http://www.law.yale.edu/documents/pdf/Faculty/TheNewSeperation ofPowers.pdf 
revisadas por las Cortes, como sucede con algunas reformas de la Constitución, por ejemplo, hace que el momento en que entran en vigencia sea más expedito. Los diseños de las tres ramas del poder público, y sus interacciones, determinan el balance que cada comunidad política considera apropiado entre limitar los abusos de poder y la rapidez con la que el Estado debe intervenir en la sociedad.

El control de constitucionalidad previo de las leyes estatutarias en Colombia es un buen ejemplo del primer argumento, aquel que se refiere a los sistemas de frenos y contrapesos. Las leyes que regulan materias de importancia notable para la comunidad política, como los derechos fundamentales, se expiden por medio de un proceso más largo y difícil que el de las leyes ordinarias. Los proyectos de ley estatutaria, una vez aprobados por el Congreso y antes de que puedan enviarse al presidente para su sanción, deben pasar por la revisión de la Corte Constitucional. El diseño institucional establecido por la Carta Política exige que las tres ramas del poder público interactúen complejamente para la aprobación de las leyes estatutarias. El constituyente determina que la intervención del Estado en la sociedad por medio de este tipo de leyes sea más lenta que con otras herramientas legales como las leyes ordinarias. Estas últimas son aprobadas sin la intervención de la rama judicial; su constitucionalidad se presume. La Corte Constitucional solo entra en acción cuando la ley es demandada.

La forma en que se diseña la rama legislativa resulta útil para ilustrar el segundo argumento, aquel que se refiere a la manera como se estructura cada una de las ramas del poder público. Un legislativo unicameral, por ejemplo, puede responder más rápidamente a las exigencias de cambio social que uno bicameral. En teoría, un Congreso compuesto por una sola cámara puede aprobar o rechazar más rápidamente un proyecto de ley. Uno bicameral exige que se dé al menos un paso más para alcanzar este mismo objetivo. El proyecto de ley tiene que ser discutido y votado en los dos órganos que componen el Congreso. Las discusiones e interacciones comunes entre la Cámara de Representantes y el Senado estadounidenses muestran las complejidades y los tiempos que genera un legislativo bicameral. La supuesta rapidez con la que se expiden las leyes en los congresos de países como Ecuador, Venezuela y Salvador ilustrarían los tiempos a los que aspira un legislativo unicameral. 
Esta segunda noción de tiempo que construye el principio de separación de poderes también es consecuencia de la interacción entre razón y naturaleza. En consecuencia, nunca podrá estar ausente de un Estado liberal de derecho. La tendencia del Estado (y de quienes lo encarnan) a abusar de su poder nunca podrá eliminarse, solo controlarse. La razón puede imaginar estructuras institucionales para limitar al Estado. No obstante, la imaginación corrupta siempre encontrará formas para superar las fronteras institucionales que se le imponen. La necesidad de que el Estado intervenga en la sociedad por medio del derecho, además, tampoco podrá eliminarse. Cuando la naturaleza humana y la naturaleza del Estado antropomorfizado se manifiestan, y no podrían dejar de hacerlo, la razón debe entrar en acción para imaginar nuevos límites que las contengan. La interacción entre naturaleza y razón es cíclica y perpetua.

\section{EL ESTADO-NACIÓN, LA UTOPÍA COSMOPOLITA Y LAS ESTRUCTURAS SUPRANACIONALES}

La geografía conceptual del principio de separación de poderes tiene hoy como principal componente el Estado-nación ${ }^{76}$. El principio supone que el espacio donde operará es el de la unidad política básica del orden internacional. Los poderes legislativo, ejecutivo y judicial se articulan como la estructura de un tipo de organización política que tiene un territorio claramente delimitado y un pueblo que habita dentro de sus fronteras. La estructura que se crea debe estar al servicio de los individuos que lo conforman. Es el instrumento que permitirá que los miembros de la comunidad política desarrollen sus potencialidades y construyan sus proyectos de buen vivir. En esta medida, el principio de separación de poderes supone la distinción entre la esfera privada y la esfera pública ${ }^{77}$. El principio opera como una guía dentro de esta última y genera un

76 Christoph Möllers, The Three Branches: A Comparative Model of Separation of Powers (Oxford Constitutional Theory), 16-17 (Oxford University Press, Oxford, 2013).

77 Michael Walzer, Liberalism and the Art of Separation, 12 Political Theory, 3, 315-330, 317 (1984). Disponible en: http://www.rationalites-contemporaines.paris-sorbonne.fr/IMG/pdf/ Walzer1.pdf 
aparataje burocrático que permite que los fines del Estado puedan materializarse.

La división tripartita del poder público disminuirá las probabilidades de que el Estado cruce la frontera que separa la órbita pública de la órbita privada. La primera es el espacio en donde se determina la estructura básica del Estado, se reparte el poder político y se determinan los criterios para distribuir los recursos escasos que controla la comunidad política. Es la esfera de la justicia. La segunda es el espacio en donde los individuos construyen sus identidades individuales y colectivas haciendo uso de la razón. Es la esfera de la moral. En un Estado liberal de derecho, el Estado es un instrumento creado por los asociados para proteger y facilitar la autonomía y la igualdad básica de todos los individuos. El Estado está al servicio de los sujetos; no viceversa. En consecuencia, aquel debe ser claramente limitado; su unidad debe ser fragmentada.

La tendencia natural del Estado y de las personas que lo controlan a abusar del poder llevará ineludiblemente a la violación del espacio íntimo en donde los individuos construyen sus proyectos de buen vivir. El Estado o sus operadores querrán limitar sus capacidades para crearlos o modificarlos; querrán también imponerles el ideal moral que consideran adecuado. El autoritarismo y el perfeccionismo moral están siempre al acecho. El liberalismo aspira, sin embargo, a que estos males sean controlados mediante el fraccionamiento del Estado. Aspira también a que el diseño y la transformación racional continua de las tres ramas del poder público logren controlar la imaginación corrupta que inventará perpetuamente formas de eludir las fronteras institucionales que la limitan.

Ahora bien, la geografía conceptual del principio tiene otras dos dimensiones, una interna y otra externa al Estado-nación. La interna hace referencia a las unidades que lo componen, en el caso de los Estados federales, los estados ${ }^{78}$. En el caso de los Estados

78 Michael C. Dorf \& Charles F. Sabel, A Constitution of Democratic Experimentalism, 98 Columbia Law Review, 2, 267-473 (1998). Disponible en: http://scholarship.law.cornell.edu/ facpub/120/. Jim Rossi, Institutional Design and the Lingering Legacy of Antifederalist Separation of Powers Ideals in the States, 52 Vanderbilt Law Review, 5, 1167-1240 (1999). Disponible en: http://papers.ssrn.com/sol3/papers.cfm?abstract_id=572082. MAXwelL A. CAMERON \& TUliA G. FALLeti, Federalism and the Subnational Separation of Power, 35 Publius, 2, 245-271 (2005). Disponible en: https://www.sas.upenn.edu/polisci/sites/www.sas.upenn.edu.polisci/files/17. Falleti(2005b)WithCameron_Publius_Federalism_Subnational_Separation_of_Powers.pdf 
Unitarios, las provincias o departamentos ${ }^{79}$. Dentro de cada una de estas unidades políticas y territoriales la estructura de gobierno debe también dividirse en tres partes. El argumento central nuevamente es que todo gobierno, así sea uno provincial, debe cumplir las tres funciones básicas que el principio presupone para todas las estructuras gubernamentales. De ahí entonces que las figuras del gobernador, las asambleas de diputados y los jueces estatales (y sus formas análogas) determinen el armazón burocrático de estas unidades de gobierno subnacionales. Alrededor de ellos se construyen los sistemas de frenos y contrapesos y se articulan las formas de colaboración armónica que permitirán la materialización de sus objetivos.

La dimensión espacial externa es la del gobierno universal o los gobiernos supranacionales. El cosmopolitanismo liberal está en tensión con la idea de las fronteras estatales ${ }^{80}$. El principio de igualdad básica de todos los seres humanos que se traduce en la igualdad básica de todos los miembros de la comunidad política entra en conflicto con la idea de ciudadanía estatal ${ }^{81}$. Solo aquellos que cumplen los criterios para determinar quién es un ciudadano pueden gozar de la protección del Estado y adquirir derechos fundamentales. Los individuos que no cumplen estos criterios, usualmente nacimiento, sangre o adopción, no se diferencian en lo sustancial de quienes sí los satisfacen. Todos son sujetos autónomos y racionales que tienen la capacidad de construir proyectos de buen vivir y un sentido de la justicia. No obstante, los extranjeros quedan por fuera de la comunidad política y sus beneficios.

Los Estados, claro, pueden ser fundamentados desde una perspectiva liberal apelando a argumentos pragmáticos relacionados

79 Colombia es un claro ejemplo de cómo el principio de separación de poderes opera dentro las estructuras político-administrativas en las que se divide el estado nación unitario. El principio de descentralización administrativa exige que en los departamentos se pueda también ver una versión de la división entre las ramas ejecutiva, legislativa y judicial. Esta aplicación, sin embargo, no es exacta. En los departamentos encontramos al gobernador, las asambleas (corporaciones administrativas que solo pueden reglamentar las normas creadas por el Congreso nacional) y las Cortes del orden nacional que tienen sede y jurisdicción en el territorio del departamento. Constitución Política [Const], 7 de julio de 1991, artículos 297303. Versión corregida, 116 Gaceta Constitucional, 20 de julio de 1991, disponible en: http:// www.secretariasenado.gov.co/senado/basedoc/constitucion_politica_1991.html

80 Christof Roos \& Lena Laube, Liberal Cosmopolitan Norms and the Border: Local Actors' Critique of the Governance of Global Processes, 15 Ethnicities, 3, 341-361 (2014).

81 Кок-Снов TAN, Justice without Borders: Cosmopolitanism, Nationalism, and Patriotism, 1-18 (Cambridge University Press, Cambridge, 2004). 
con la distribución efectiva de recursos escasos, la solidaridad que se genera frente a quienes están más próximos física y emocionalmente o la importancia que tiene la cohesión social para la acción colectiva $^{82}$. Sin embargo, estas justificaciones están en tensión con el concepto de individuo que está en la base del liberalismo. El liberalismo parece ineludiblemente comprometido con la utopía cosmopolita y con la construcción de un Estado universal que acoja a todos los miembros de la especie ${ }^{83}$. Este nuevo espacio político no puede dejar de imaginarse a partir del principio de separación de poderes. El gobierno de todos los seres humanos tendrá las mismas funciones básicas de los Estados-nación. El leviatán universal tendrá también que crear derecho, administrar la comunidad política y resolver sus conflictos sociales haciendo uso de normas jurídicas preexistentes. La única diferencia es que sus límites espaciales estarán marcados por los límites del globo terráqueo. El territorio del gobierno de todos los seres humanos será el planeta entero.

Los gobiernos supranacionales constituyen la otra dimensión externa al Estado-nación que hace parte de la geografía conceptual del principio de separación de poderes ${ }^{84}$. El ejemplo paradigmático es el de la Unión Europea ${ }^{85}$. La complejidad de su estructura institucional no encaja en el modelo simple de tres ramas del poder público claramente diferenciables. No obstante, el principio sí es la guía que les da forma. Por un lado, el Parlamento europeo y el Consejo de la Unión Europea concentran el poder creador de derecho. Cada uno representa intereses distintos: el primero a los ciudadanos de la Unión; el segundo, a los Estados miembros. Por el otro lado, el Tribunal Europeo de Justicia centraliza el poder judicial. Finalmente, la Comisión Europea aglutina las labores de administración y aplicación de los tratados de la Unión. El Tribunal de Cuentas y el Banco Central Europeo son dos ejemplos de las instituciones que no pueden encajarse sencillamente en la división

82 KoK-Chor TAn, Justice without Borders: Cosmopolitanism, Nationalism, and Patriotism, 86106, 180-197 (Cambridge University Press, Cambridge, 2004).

83 KoK-Chor TAn, Justice without Borders: Cosmopolitanism, Nationalism, and Patriotism, 62-84 (Cambridge University Press, Cambridge, 2004).

84 Christoph Möllers, The Three Branches: A Comparative Model of Separation of Powers (Oxford Constitutional Theory), 150-226 (Oxford University Press, Oxford, 2013).

85 Gerard Conway, Recovering a Separation of Powers in the European Union, 17 European Law Journal, 3, 304-322 (2011). Disponible en: http://papers.ssrn.com/sol3/papers.cfm? abstract_id=2246210 
tripartita clásica del poder público. Las estructuras supranacionales, como lo ilustra este ejemplo, se imaginan también a partir del principio de separación de poderes. Estas formas de organización política, que incluyen pero superan a los Estados nacionales, no escapan al poder que tiene este principio dentro de la imaginación moderna e ilustrada. 


\section{CONCLUSIONES}

La arquitectura conceptual del principio de separación de poderes tiene tres componentes fundamentales: un sujeto individual y un sujeto colectivo interdependientes; un concepto de tiempo circular e infinito que es función de la oposición conceptual entre naturaleza y razón; y un concepto de espacio que gira en torno a las ideas de Estado-nación, gobierno universal y estructuras supranacionales. Explorar estas categorías permite comprender una parte importante de la imaginación jurídica y política moderna e ilustrada que sigue controlando la vida de las democracias liberales contemporáneas. Estas categorías contribuyen a la creación de la identidad de las personas y colectividades que habitan los Estados que se organizan alrededor de esta forma de interpretar y estructurar una comunidad política. Comprender es un prerrequisito para evaluar; discernir la arquitectura conceptual de nuestra imaginación jurídica y política es una condición necesaria para una buena deliberación y acción normativas. 


\section{BIBLIOGRAFÍA}

\section{Libros}

Austin, John, The Province of Jurisprudence Determined (Wilfrid E. Rumble, Cambridge, 1832-1995).

Bentham, Jeremy, A Fragment on Government (J. H. Burns \& H. L. A. Hart, Cambridge, 1776-1988).

Bentham, Jeremy, An Introduction to the Principles of Morals and Legislation (J. H. Burns \& H. L. A. Hart, Oxford, 1780-1996).

Blackstone, William, Commentaries on the Laws of England (Clarendon Press, Oxford, $1765)$.

García-Villegas, Mauricio, La eficacia simbólica del derecho: examen de situaciones colombianas (Ediciones Uniandes, Bogotá, 1994).

Hamilton, Alexander; Madison, James \& Jay, John, El federalista (Fondo de Cultura Económica, FCE, México, 2001).

Hesse, Joachim Jens \& Johnson, Nevil, eds., Constitutional Policy and Change in Western Europe (Oxford University Press, Oxford, 1995).

Hobbes, Thomas, Leviatán (Fondo de Cultura Económica, FCE, México, 1987).

Kahn, Paul W., The Cultural Study of Law: Reconstructing Legal Scholarship (Chicago University Press, Chicago, 1999).

Laski, Harold J., Authority in the Modern State (Yale University Press, London, 1919). Disponible en: http://constitutiolibertatis.hautetfort.com/files/LaskiHauthority. pdf

Laver, Michael \& Shepsle, Kenneth A., Making and Breaking Governments: Cabinets and Legislatures in Parliamentary Democracies (Cambridge University Press, Cambridge, 1996).

Lazare, Daniel, The Frozen Republic: How The Constitution Is Paralyzing Democracy (Harcourt Brace \& Company, New York, 1996).

Levinson, Sanford, ed., Responding to Imperfection. The Theory and Practice of Constitutional Amendment (Princeton University Press, Princeton, 1995).

Locke, John, Segundo tratado sobre el gobierno civil (SKLA, Bogotá, D.C., 2012).

Mangabeira-Unger, Roberto, Politics: The Central Texts (Verso, London, 1997).

Möllers, Christoph, The Three Branches: A Comparative Model of Separation of Powers (Oxford Constitutional Theory) (Oxford University Press, Oxford, 2013).

Montesquieu, Charles Louis Secondat de, Del espíritu de las leyes, 104 (Editorial Porrúa, México, 1998).

Pufendorf, Samuel von, Of the Law of Nature and Nations (J. Walthoe, R. Wilkin \& J. Bonwick, London, 1717).

RaWls, John, Liberalismo político (Fondo de Cultura Económica, FCE, Bogotá, 1996). 
Sartori, Giovanni, Comparative Constitutional Engineering ( $2^{\mathrm{a}} \mathrm{ed}$., New York University Press, New York, 1997).

Sundquist, James L., Constitutional Reform and Effective Government (rev. ed., The Brookings Institution, Washington, 1992).

TAn, Koк-Chor, Justice without Borders: Cosmopolitanism, Nationalism, and Patriotism, 1-18 (Cambridge University Press, Cambridge, 2004).

Vattel, Emer de, The Law of Nations; or, Principles of the Law of Nature, Applied to the Conduct and Affairs of Nations and Sovereigns (London, 1760). Disponible en: http://oll.libertyfund.org/titles/2246

VILE, M. J. C., Constitucionalismos y separación de poderes (Centro de Estudios Políticos y Constitucionales, CEPC, Madrid, 2007).

Voigt, Stefan, Explaining Constitutional Change. A Positive Economics Approach (New Thinking in Political Economy) (Edward Elgar Publishing, London, 1999).

\section{Contribución en obras colectivas}

Boucher, David \& Kelly, Paul, The Social Contract and its Critics: An Overview, en The Social Contract from Hobbes to Rawls, 1-34 (David Boucher \& Paul Kelly, eds., Routledge, London, 2005).

Buchely, Lina, Más allá del modelo weberiano: el debate sobre las burocracias y el Estado - Ensayo preliminar, en Las Burocracias, 11-95 (Akhil Gupta, Michael Lipsky, Aradhana Sharma \& Charles Wright-Mills, Universidad de los Andes, Bogotá, 2014).

DAHL, RoBert, Thinking about Democratic Constitutions: Conclusions from Democratic Experience, en Political Order: Nomos XXXVIII, 175-206 (IAN Shapiro \& Russell Hardin, eds., New York University Press, New York, 1996).

Hesse, Joachim Jens \& Johnson, Nevil, eds., Constitutional Policy and Change in Western Europe (Oxford University Press, Oxford, 1995).

King, Anthony, 'Chief Executives' in Western Europe, en Developing Democracy: Comparative Research in Honour of J. F.P. Blondel, 150-163 (IAN BUdGe \& David MCKAY, eds., Sage, London, 1994).

Linz, Juan J., Presidential or Parliamentary Democracy: Does It Make A Difference?, en The Failure of Presidential Democracy, 3-89 (Juan J. Linz \& Arturo Valenzuela, eds., The Johns Hopkins University Press, Baltimore, 1994).

Mainwaring, Scott, Presidentialism, Multipartism, and Democracy: The Difficult Combination, en Flying Blind: Emerging Democracies in East Central Europe, 55-85 (Gyorgy Szoboszlai, ed., Hungarian Political Science Association, Budapest, 1992).

Mainwearing, Scott \& Shugart, Matthew S., Juan Linz, Presidentialism, and Democracy: A Critical Appraisal, 29 Comparative Politics, 4, 449-471 (1997).

Nino, Carlos Santiago, Transition to Democracy, Corporatism, and Presidentialism with Special Reference to Latin America, en Constitutionalism and Democracy: Transitions in the Contemporary World, 46-64 (Douglas Greenberg, Stanley 
N. Katz, Melanie Beth Oliviero \& Steven Wheatley, eds., Oxford University Press, Oxford, New York, 1993).

Preuss, Ulrich K., Patterns of Constitutional Evolution and Change in Eastern Europe, en Constitutional Policy and Change in Western Europe, 95-127 (JoACHIM Jens Hesse \& Nevil Johnson, eds., Oxford University Press, Oxford, 1995).

Sartori, Giovanni, Neither Presidentialism nor Parliamentarianism, en The Failure of Presidential Democracy, 106-118 (Juan J. Linz \& Arturo Valenzuela, eds., The Johns Hopkins University Press, Baltimore, 1994).

Stepan, Alfred \& Skach, Cindy, Presidentialism and Parliamentarianism in Comparative Perspective, en The Failure of Presidential Democracy, 119-136 (JuAn J. Linz \& Arturo Valenzuela, eds., The Johns Hopkins University Press, Baltimore, 1994).

\section{Revistas}

Ackerman, Bruce, The New Separation of Powers, 113 Harvard Law Review, 3, 633729 (2000). Disponible en: http://www.law.yale.edu/documents/pdf/Faculty/ TheNewSeperationof Powers.pdf

Barreto-Rozo, Antonio, El proyecto constitucional de la separación de poderes en el Estado colombiano: apuntes sobre su desenvolvimiento a lo largo del siglo XX, 122 Vniversitas, 213-260 (2011). Disponible en: http://www.redalyc.org/ pdf/825/82522606009.pdf

Binder, Sarah A., The Dynamics of Legislative Gridlock, 1947-96, 93 The American Political Science Review, 3, 519-533 (1999). Disponible en: http://www.jstor.org/ stable/2585572?seq=1\#page_scan_tab_contents

Cameron, Maxwell A. \& Falleti, Tulia G., Federalism and the Subnational Separation of Power, 35 Publius, 2, 245-271 (2005). Disponible en: https://www.sas.upenn.edu/ polisci/sites/www.sas.upenn.edu.polisci/files/17.Falleti(2005b)WithCameron Publius_Federalism_Subnational_Separation_of_Powers.pdf

Cheibub, José Antonio; Elkins, Zachary \& Ginsburg, Tom, Latin American Presidentialism in Comparative and Historical Perspective, 89 Texas Law Review, 7, 1707-1740 (2011). Disponible en: http://www.texaslrev.com/wp-content/uploads/ Cheibub-Elkins-Ginsburg-89-TLR-1707.pdf

Conway, Gerard, Recovering a Separation of Powers in the European Union, 17 European Law Journal, 3, 304-322 (2011). Disponible en: http://papers.ssrn.com/sol3/papers. cfm?abstract_id $=2246210$

Díaz-Bravo, Enrique, Desarrollo histórico del principio de separación de poderes, 38 Revista de Derecho, Universidad del Norte, 240-270 (2012). Disponible en: http:// www.redalyc.org/pdf/851/85124997008.pdf

Dorf, Michael C. \& Sabel, Charles F., A Constitution of Democratic Experimentalism, 98 Columbia Law Review, 2, 267-473 (1998). Disponible en: http://scholarship. law.cornell.edu/facpub/120/

Fernández-Albertos, José, Dividir lo indivisible: separación de poderes y soberanía popular en James Madison, 128 Revista de Estudios Políticos, 293-316 (2005). Disponible en: http://digital.csic.es/bitstream/10261/20727/1/REP128.011.pdf 
Flaherty, Martin S., The Most Dangerous Branch, 105 Yale Law Journal, 7, 1725-1840 (1996).

Gauthier, David, The Social Contract as Ideology, 6 Philosophy \& Public Affairs, 2, 130-164 (1977).

Herrera-Robles, Aleksey, Análisis práctico sobre los criterios de distinción de las funciones públicas, 17 Revista de Derecho, Universidad del Norte, 143-161, 147-150 (2002). Disponible en:_rcientificas.uninorte.edu.co/index.php/derecho/article/ view/2991

HuQ, Azız Z., Libertarian Separation of Powers, 8 New York University Journal of Law and Liberty, 3, 1006-1039 (2013-2014). Disponible en: http://static1.squarespace.com/ static/514e1ca0e4b04c6ad1834313/t/55e78d02e4b018b9867be56d/1441238274220/ huq.pdf

Katyal, Neal Kumar, Internal Separation of Powers: Checking Today's Most Dangerous Branch from Within, 115 Yale Law Journal, 9, 2314-2349 (2006). Disponible en: $\mathrm{http}: / / \mathrm{ww} w . y a l e l a w j o u r n a l . o r g / e s s a y / i n t e r n a l-s e p a r a t i o n-o f-p o w e r s-c h e c k i n g-$ todays-most-dangerous-branch-from-within

Lijphart, Arend, Constitutional Choices for New Democracies, 2 Journal of Democracy, 1, 72-84 (1991). Disponible en: http://www.researchgate.net/publication/236769539_ Constitutional_Choices_for_New_Democracies

Lucas-Garín, Andrea, Nuevas dimensiones del principio de división de poderes en un mundo globalizado, 7 Estudios Constitucionales, 2, 241-253 (2009). Disponible en: http://www.redalyc.org/articulo.oa?id=82011841009

Lutz, Donald, Toward a Theory of Constitutional Amendment, 88 American Political Science Review, 2, 355-370 (1994). Disponible en: http://www.jstor.org/ stable/2944709?seq=1\#page_scan_tab_contents

Magill, M. Elizabeth, Beyond Powers and Branches in Separation of Powers Law, 150 University of Pennsylvania Law Review, 2, 603-660 (2001-2002). Disponible en: http:// scholarship.law.upenn.edu/cgi/viewcontent.cgi?article $=3259 \&$ context $=$ penn law_review

Magill, M. Elizabeth, The Real Separation in Separation of Powers Law, 86 Virginia Law Review, 6, 1127-1198 (2000). Disponible en: https://law.stanford.edu/publications/ the-real-separation-in-separation-of-powers-law/, http://papers.ssrn.com/sol3/ papers.cfm?abstract_id=224797

Moe, Terry M. \& Caldwell, Michael, The Institutional Foundations of Democratic Government: A Comparison of Presidential and Parliamentary Systems, 150 Journal of Institutional and Theoretical Economics, 1, 171-195 (1994).

Negretto, Gabriel L., Diseño constitucional y separación de poderes en América Latina, 65 Revista Mexicana de Sociología, 1, $41-76$ (2003). Disponible en: http://www. ejournal.unam.mx/rms/2003-1/RMS03102.pdf

Nourse, Victoria, The Vertical Separation of Powers, 49 Duke Law Journal, 3, 749-802 (1999-2000). Disponible en: http://scholarship.law.duke.edu/cgi/viewcontent. cgi? article $=1068 \&$ context $=\mathrm{dlj}$

Oprisko, Robert L. \& Kaliher, Kristopher, The State as a Person?: Anthropomorphic Personification vs. Concrete Durational Being, 6 Journal of International and 
Global Studies, 1, 30-49 (2014). Disponible en: http://papers.ssrn.com/sol3/papers. cfm?abstract_id=2535494

Ratnapala, Suri, John Locke's Doctrine of the Separation of Powers: A Re-Evaluation, 38 American Journal of Jurisprudence, 1, 189-220 (1993). Disponible en: http:// scholarship.law.nd.edu/cgi/viewcontent.cgi?article $=1205 \&$ context $=$ ajj

Rogoff, Martin A., A Comparison of Constitutionalism in France and the United States, 49 Maine Law Review, 1, 21-84 (1997). Disponible en: http://mainelaw.maine.edu/ wp-content/uploads/2014/01/rogoff-mlr-49.pdf

Roos, Christof \& Laube, Lena, Liberal Cosmopolitan Norms and the Border: Local Actors' Critique of the Governance of Global Processes, 15 Ethnicities, 3, 341-361 (2014).

Rossi, Jim, Institutional Design and the Lingering Legacy of Antifederalist Separation of Powers Ideals in the States, 52 Vanderbilt Law Review, 5, 1167-1240 (1999). Disponible en: http://papers.ssrn.com/sol3/papers.cfm?abstract_id=572082

Skinner, Quentin, Una genealogía del Estado moderno, 118 Estudios Públicos, 5-56 (2010). Disponible en: http://www.cepchile.cl/dms/archivo_4626_2792/rev118_Skinner. pdf

SolozÁbal-Echavarría, JuAn José, Sobre el principio de separación de poderes, 24 Revista de Estudios Políticos, 215-235, 230-234 (1981). Disponible en: http://dialnet. unirioja.es/servlet/articulo?codigo $=26674$

Sunstein, Cass R. \& Lessig, Lawrence, The President and the Administration, 94 Columbia Law Review, 1, 1-123 (1994). Disponible en: http://chicagounbound. uchicago.edu/cgi/viewcontent.cgi?article=11680\&context=journal_articles

Tarapués-Sandino, Diego Fernando, El tribunal constitucional como poder autónomo en el sistema político colombiano, 1 Criterio Jurídico, 7, 163-183 (2007). Disponible en: http://revistas.javerianacali.edu.co/index.php/criteriojuridico/article/ view/276/1060

Uprimny, Rodrigo, Separación de poderes y forma de gobierno en Colombia: comentarios al documento de la Misión Alesina, 3 Revista de Economía Institucional, 5, 146167 (2001). Disponible en: http://www.economiainstitucional.com/pdf/No5/ ruprimny5.pdf

Waldron, Jeremy, Theoretical Foundations of Liberalism, 37 The Philosophical Quarterly, 147, 127-150 (1987).

Walzer, Michael, Liberalism and the Art of Separation, 12 Political Theory, 3, 315-330 (1984). Disponible en: http://www.rationalites-contemporaines.paris-sorbonne. fr/IMG/pdf/Walzerl.pdf

Wendt, Alexander, How Not to Argue Against State Personhood: A Reply to Lomas, 31 Review of International Studies, 2, 357-360 (2005). Disponible en: http://www. jstor.org/stable/40072101?seq=1\#page_scan_tab_contents

Wendt, Alexander, The State as Person in International Theory, 30 Review of International Studies, 2, 289-316 (2004). Disponible en: http://www.jstor.org/ stable/pdf/20097917.pdf?seq=1\#page_scan_tab_contents 


\section{Working paper}

Negretto, Gabriel L., The Durability of Constitutions in Changing Environments: Explaining Constitutional Replacement in Latin America (University of Notre Dame, The Helen Kellogg Institute for International Studies, Working Paper No. 350, 2008). Disponible en: http://kellogg.nd.edu/publications/workingpapers/ WPS/350.pdf

\section{Normatividad colombiana}

Constitución Política [Const], 7 de julio de 1991, artículo 113. Versión corregida, 116 Gaceta Constitucional, 20 de julio de 1991, disponible en: http://www. secretariasenado.gov.co/senado/basedoc/constitucion_politica_1991.html

\section{Jurisprudencia colombiana}

Corte Constitucional, Sentencia C-246-04, 16 de marzo de 2004, magistrada ponente Clara Inés Vargas-Hernández. Disponible en: http://www.corteconstitucional. gov.co/relatoria/2004/C-246-04.htm

\section{Publicaciones de internet}

Carolan, Eoin, The Problems with the Theory of the Separation of Powers. Disponible en: http://ssrn.com/abstract $=1889304$

Charles LeBrun, The Most Important Painter in $17^{\text {th }}$ Century France, First painter to King Louis XIV. Disponible en: http://www.charleslebrun.com/site_anglais/ qui_est_lebrun_english.htm 